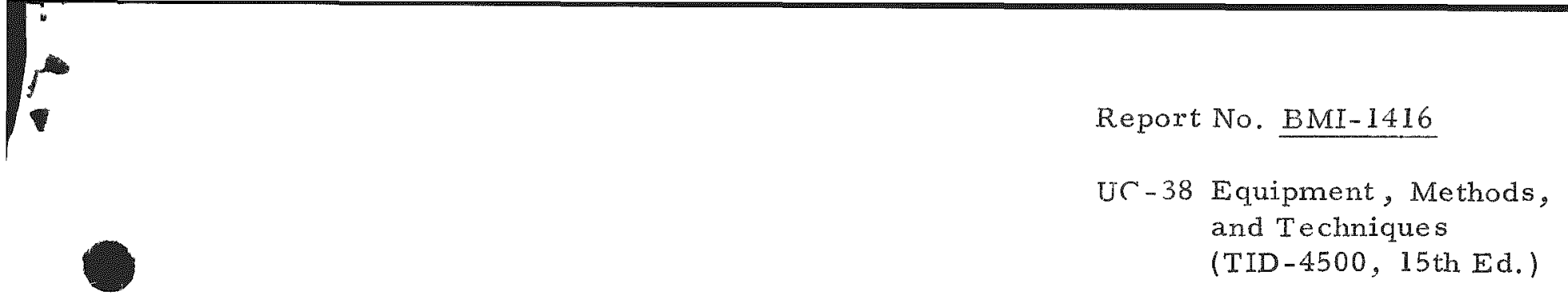

Navy Department, Bureau of Ships

Contract No. NObs -67500

Bettis Subcontract No. $73-(00-929)$

EXAMINATION OF A NONREGENERATIVE HEAT EX CHANGER

FROM THE U.S.S. NAUTILUS (SSN-571)

by

Warren E. Berry

Oliver M. Stewart

Frederick W. Fink

February 19, 1960

BATTELLE MEMORIAL INSTITUTE

505 King Avenue

Columbus 1, Ohio 


\section{DISCLAIMER}

This report was prepared as an account of work sponsored by an agency of the United States Government. Neither the United States Government nor any agency Thereof, nor any of their employees, makes any warranty, express or implied, or assumes any legal liability or responsibility for the accuracy, completeness, or usefulness of any information, apparatus, product, or process disclosed, or represents that its use would not infringe privately owned rights. Reference herein to any specific commercial product, process, or service by trade name, trademark, manufacturer, or otherwise does not necessarily constitute or imply its endorsement, recommendation, or favoring by the United States Government or any agency thereof. The views and opinions of authors expressed herein do not necessarily state or reflect those of the United States Government or any agency thereof. 


\section{DISCLAIMER}

Portions of this document may be illegible in electronic image products. Images are produced from the best available original document. 
TABLE OF CONTENTS

Page

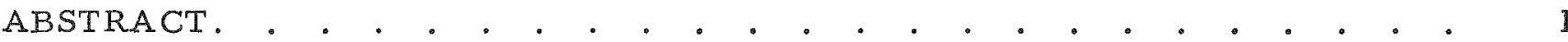

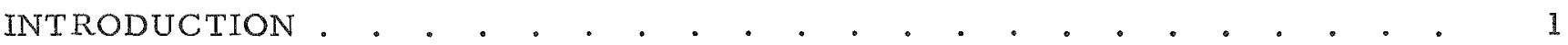

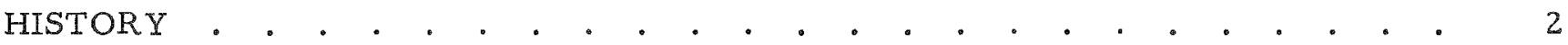

Details of Construction. . . . . . . . . . . . . . . . . 2

Operating Conditions . . . . . . . . . . . . . . . . . 2

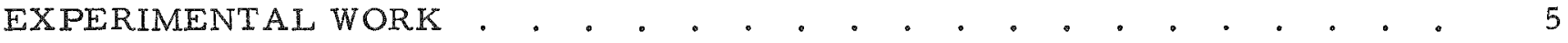

Examination Procedures . . . . . . . . . . . . . . . . . 5

Leak Testing . . . . . . . . . . . . . . . . . 5

Cutting and Numbering . • . . . . . . . . . . . . . 6

Decontamination . . . . . . . . . . . . . . 6

Descaling . . . . . . . . . . . . . . . . . . 10

Evaluation . . . . . . . . . . . . . . . . . . 11

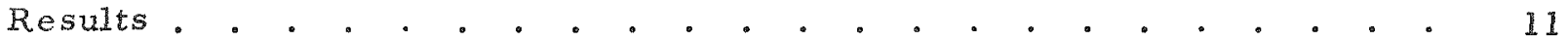

General Appearance of Areas Examined . . . . . . . . . . 11

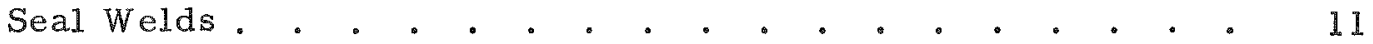

Tube Sheets in Drain Area. . . . . . . . . . . . . 11

Tube Sheets Contacting Secondary Water. . . . . . . 15

Exposed Tubing . . . . . . . . . . . . . . . 15

Fully Exposed Tubes . . . . . . . . . . . . . . . . 15

Tube Stubs From Tube Sheets . . . . . . . . . . . . . 24

Tube Sheets Surrounding Tube Stubs . . . . . . . . . . . 38

Flat Surfaces of Tube Sheets . . . . . . . . . . . . . 41

Baffle Plates... . . . . . . . . . . . . . . . 41

Seal Welds... . . . . . . . . . . . . . . . 46

DISCUSSION . . . . . . . . . . . . . . . . . 46

CONCLUSIONS . . . . . . . . . . . . . . . . 52

ACKNOWLEDGMENTS 。 . . . . . . . . . . . . . . 52

REFERENCES. . . . . . . . . . . . . . . . . 53 


\title{
EXAMINATION OF A NONREGENERATIVE HEAT EXCHANGER FROM THE U.S.S. NAUTILUS (SSN-571)
}

\author{
Warren E. Berry, Oliver M. Stewart, \\ and Frederick W. Fink
}

\begin{abstract}
Selected components from a stainless steel nonregenerative heat exchanger removed from the ('.S.S. Vautilus (SSV-571) have been examined for evidence of stress-corrosion cracking. The examination was conducted on three baffle plates, all primary-face seal u'elds, and the tubes and the surrounding tube sheets of 7 out of a total of 35 tubes. Maximum operating temperature of the heat exchanger was $260 \mathrm{~F}$ for the inlet primary water and $164 \mathrm{~F}$ for the exit secondary uater. Chloride content of the sccondary uater averaged $5 \mathrm{ppm}$, with a maximum of $15 \mathrm{ppm}$.
\end{abstract}

Only one suspected stress-corrosion crack was found in the components normally in contact with the secondary water. The crach, 2.5 mils in depth, was located on a fullv exposed tube. it the 95 per cent confidence level this represented a probability of finding cracking on fully exposed surfaces in 0 to 60 per cent of the rest of the tubes in the heat exchanger. Severe stress-corrosion craching was found in tubes in the tube-sheet drain area at the juncture with the inner tube sheet at the inlet end, where secondary water seeped past the expanded tubes. Cracks were detected in five of seven tubes for a statistical probability of 25 to 96 per cent at the 95 per cent confidence level. VIaximum depth of cracks u as 28 mils or 80 per cent penetrotion of the 35-mil-thich tubing wall. Stresscorrosion crachs also were found around several holes on the drain-side tube-sheet surfaces at the inlet end. "laximum depth was 12 mils, which did not seriously threaten penetration of the 9'16-in.-thick tube sheet.

Cracks were detected in 5 of 35 primarn-face seal welds at the inlet end and in 11 of 35 at the outlet end. This behavior was attributed to hot-short cracking of the Type 347 stainless steel weldments rather than to stress corrosion.

\section{INTRODUCTION}

A stainless steel nonregenerative heat exchanger was removed from the U.S.S. Nautilus (SSN-571) for examination. The examination was conducted at Battelle for the Bettis Laboratory, operated for the Atomic Energy Commission by the Westinghouse Electric Corporation. The Bettis Laboratory was the prime contractor for designing and constructing reactor components in the above installation.

The nonregenerative heat exchanger had no history of leakage. However, leakage had been observed in stainless steel water coolers in the Nautilus which were operated at higher temperatures, but with the same cooling water. $(1,2)$ These leaks were attributed to chloride stress-corrosion cracking of the water-cooler tubing. Maximum operating temperature in the nonregenerative unit was $260 \mathrm{~F}$ for the primary inlet water and $164 \mathrm{~F}$ for the secondary outlet water. Stress-corrosion cracking was not expected to be severe under these conditions, because of the low temperatures involved. However, it has been shown that austenitic stainless steels are susceptible to stress cracking in water containing as little as 5 to 10 ppm chlorides at temperatures ranging

(1) References at end of report. 
from 165 to $200 \mathrm{~F}$. (3) Thus, it was desirable to learn the nature and extent of cracking (if any) in the nonregenerative heat exchanger to determine its suitability for this application.

\section{HISTORY}

\section{Details of Construction}

The nonregenerative heat exchanger was constructed entirely of AISI Type 347 stainless steel. It was a horizontal, straight-tube, single-pass, double-tube-sheet unit. The unit was cylindrical in shape and had an over-all length of about $17 \mathrm{ft} 9 \mathrm{in}$. and a shell diameter of $3-1 / 2$ in. A photograph of the unit as received at Battelle is shown in Figure 1 .

The nonregenerative heat exchanger contained thirty-five $1 / 4$-in.-diameter tubes having 0.035 -in. wall thickness. Over-all, the tubes were approximately $16 \mathrm{ft}$ long. The tubes were expanded into the inner tube sheets and were sealed by manual heliarc welding at the primary face of the outer tube sheets. The tube centers in the tube sheets were located at the vertices of equilateral triangles $3 / 8 \mathrm{in}$. on a side. Tube sheets were $9 / 16 \mathrm{in}$. thick. There was a $3 / 4-\mathrm{in}$. spacing between tube sheets to provide for the tube-sheet drain. The thickness of the heat-exchanger shell was 0.300 in.

Primary water was introduced through 1 -in. pipe fittings and secondary water through 1-1/2-in. fittings. The connection to the tube-sheet drain was 1/2-in. pipe. There were 48 baffles within the heat exchanger which separated the tubes and insured complete contact with the secondary water. Baffles were spaced about 4-1/16 in. apart.

\section{Operating Conditions}

The nonregenerative heat exchanger was part of the purification circuit and provided the final cooling of a bypass flow of primary water prior to its entry into the demineralizer. A schematic diagram of the flow circuit is shown in Figure 2. The bypass flow of primary water first entered the hydraulic service system which provided the hydraulic-pressure differential required for activating cylinder-operated valves. It then passed through a $U$-shaped regenerative heat exchanger where the primary water was cooled to $260 \mathrm{~F}$ and then through the nonregenerative unit where it was further cooled to $120 \mathrm{~F}$. The primary water then went through the demineralizer, back through the secondary side of the regenerative heat exchanger, and, finally, back into the main coolant stream.

The coolant for the nonregenerative heat exchangex was fresh water. It entered the unit at $110 \mathrm{~F}$ and left at $164 \mathrm{~F}$. The cooling-water flow was countercurrent to the primary-water flow. The fresh-water cooling system was a closed circuit and, in addition to the nonregenerative heat exchanger, served the following units: 


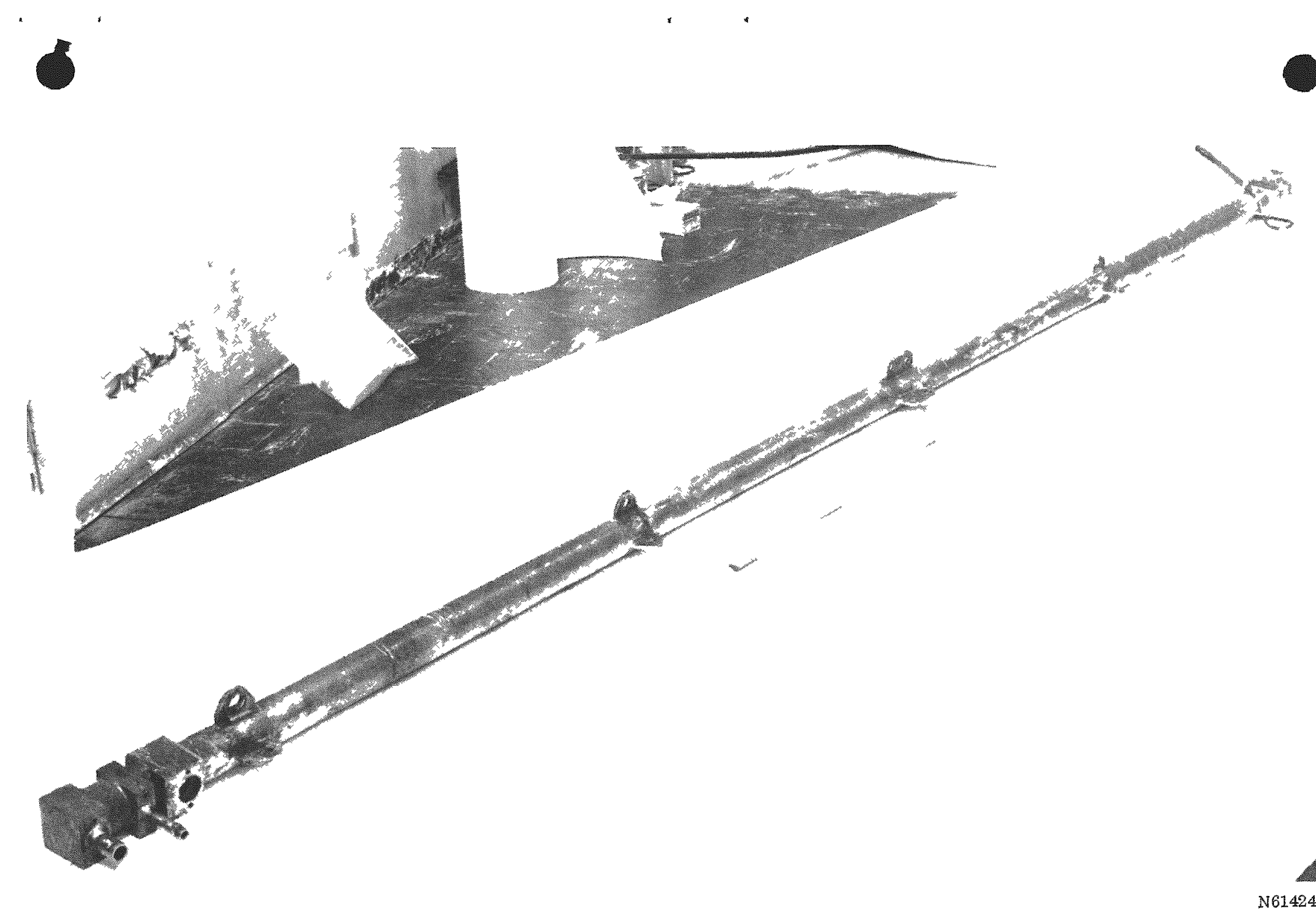

FIGURE 1. APPEARANCE OF NONREGENERATIVE HEAT EXCHANGER AS RECEIVED AT BATTELLE

Openings at the inlet end in the left foreground are for primary water, tube-sheet drain, and secondary water as viewed from left to right. 


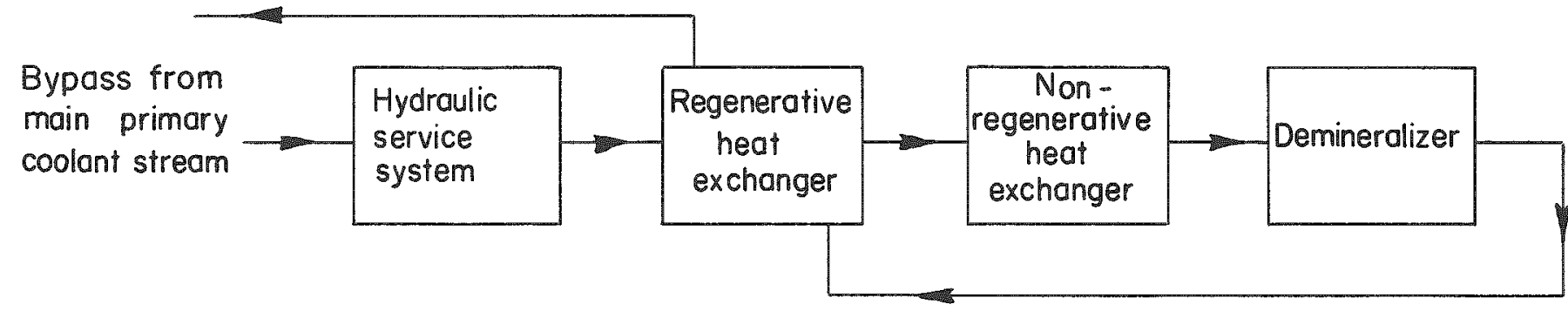

\section{$0-25963$}

FIGURE 2. SCHEMATIC DIAGRAM SHOWING THE POSITION OF THE NONREGENERATIVE HEAT EXCHANGER IN THE WATER-PURIFICATION CIRCUIT 
(1) Neutron-shield tank

(2) Main primary-coolant pumps

(3) Hydraulic service pumps

(4) Sampling-system cooler

(5) Rod-drive motors

(6) Lower-level air-conditioning unit during emergency shutdown of the air-conditioning system.

The fresh water in turn was cooled in fresh water-sea water heat exchangers. These units also were of the single-pass shell-and-tube type with double tube sheets. Sea water passed through the tubes and fresh water through the shell and around the tubes. The tubes, which were copper-nickel alloy, were expanded into both the inner steel and outer copper-nickel tube sheets and were flared into the outer tube sheet. The tube sheets were bolted to the shell (water box) with rubber O-rings providing the seal.

The fresh-water system included drinking water and evaporator water. The drinking water contained 10 to $15 \mathrm{ppm}$ chlorides and the evaporator water contained about 1 ppm chlorides. Up until 1958, drinking water was added as makeup water. Since that time, evaporator water had been used in makeup. Prior to 1958 , the chloride content of the fresh water averaged about 5 ppm for long periods of time, and may have been as high as $15 \mathrm{ppm}$ on occasion. (2). Since about mid-1958, chlorides were controlled to less than 1 ppm. Oxygen concentrations of 4 to 6 ppm have been detected in the fresh water. (1)

The nonregenerative heat exchangex was part of the original installation on the Nautilus. When removed in July, 1959, it had been in operation approximately 4-1/2 years. Maximum operating pressures had been 2200 psi on the primary side and $75 \mathrm{psi}$ on the secondary (shell) side of the heat exchanger.

\section{EXPERIMENTAL WORK}

\section{Examination Procedures}

\section{Leak Testing}

The heat exchanger was leak tested in the following manner:

(1) The as-received unit was pressurized to 16 psia helium on the primary side and helium leak detector was connected to the secondary side. This method would detect leaks in the entire unit but not of individual tubes. No leaks were detected. 
(2) The primary heads of the exchanger were cut off and the secondary side was pressurized to 120 psia. The primary-face seal welds at either end were swabbed with soap solution to detect which tubes might be leaking. No leaks were detected.

(3) The tube-sheet drains were then pressurized to 120 psia. Soap solution again was swabbed over the primary faces to detect leaks in the seal welds. No leaks were detected.

(4) Finally, the outer tube sheet was cut from each end and the secondary side again was pressurized to 120 psia. Soap solution was swabbed around the tube stubs on the drain side of the inner tube sheets to detect leaks around the expanded tubes. No leaks were detected.

\section{Cutting and Numbering}

The heat exchanger was cut as shown in Figure 3. All cutting operations were made with a power hacksaw. After removal of the primary heads, the outer tube sheets were removed (by cutting at A). The tubes were then cut about $1 / 2 \mathrm{in}$. from the secondary face of the inner tube sheets (B). The tubes were also cut in the middle (C) to facilitate handling. The tubes were then easily removed from the baffle plates except where they were twisted near the inlet end. Two additional cuts (D) were required to remove these tubes.

The tube stubs were removed from the tube sheets by an effective method suggested by Bettis. The method is illustrated in Figure 4. The seal welds were first separated from the tubes by a transverse cut through the tube sheet about $1 / 4 \mathrm{in}$. from the seal welds. Next, longitudinal cuts were made in the tube sheet between the tubes to remove individual tubes. Slots were then cut through the tube sheet to the surface of the tubes as shown in the bottom of Figure 4. Finally, the tube sheet and tube stub were separated by placing "off-center" in a vise. This technique resulted in very little damage to the tubing surface.

The 35 tubes were arbitrarily numbered as shown in Figure 5. As viewed from the inlet end and looking toward the outlet end, the tube-sheet drain was assumed to be the bottom of the heat exchangex. The tubes were numbered in accordance with this assumption, the top of each tube being designated 12:00 o'clock. The location of a crack or defect was identified as to the tube number, distance from the inlet pximary face (seal welds), and position on the circumference of the tube (clock designation as viewed from the inlet end looking toward the outlet end).

\section{Decontamination}

Radioactivity at the shell surface of the as-received heat exchanger was less than $30 \mathrm{mr}$ per hr. Since the principal source of the radioactivity was the corrosion product from the primary water, the inside of the tubes was decontaminated. The citric aciddisodium EDTA process specified in MIL-STD-711(Ships), May 8, 1959, was employed. The conditions under which this bath is used are presented in Table 1. 


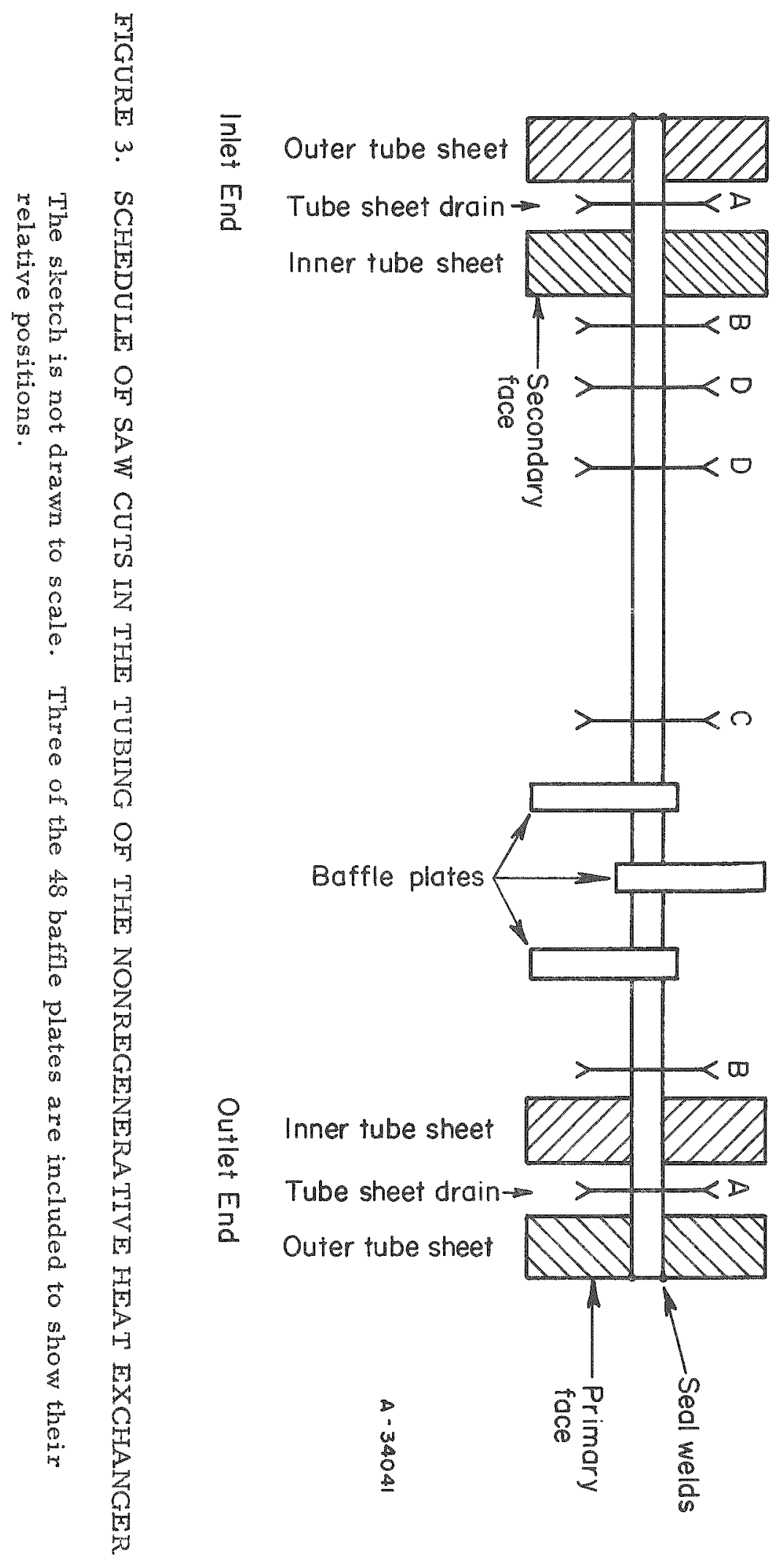



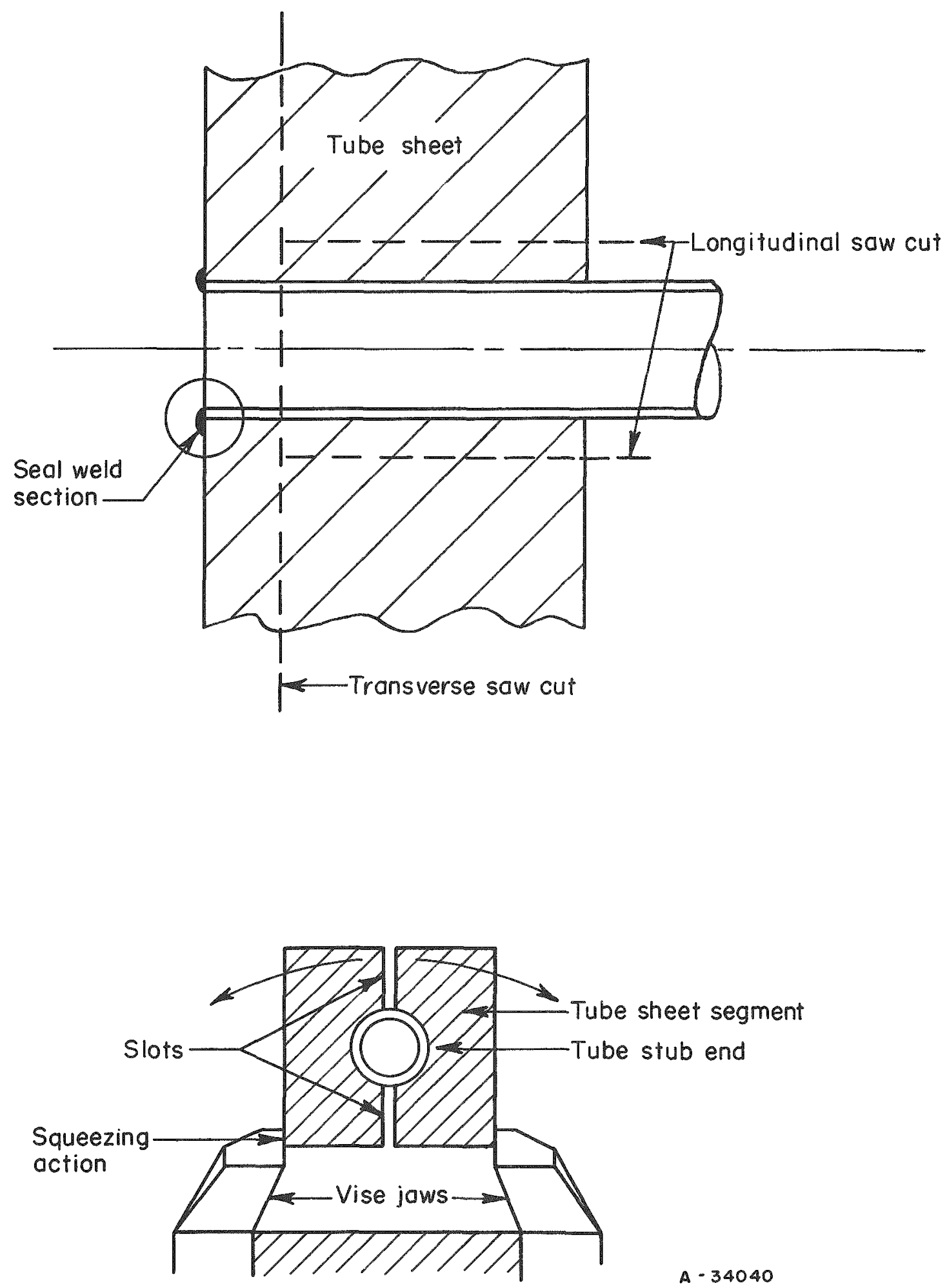

FIGURE 4. METHOD OF REMOVAL OF TUBE STUBS FROM TUBE SHEETS Drawing is not to scale. 


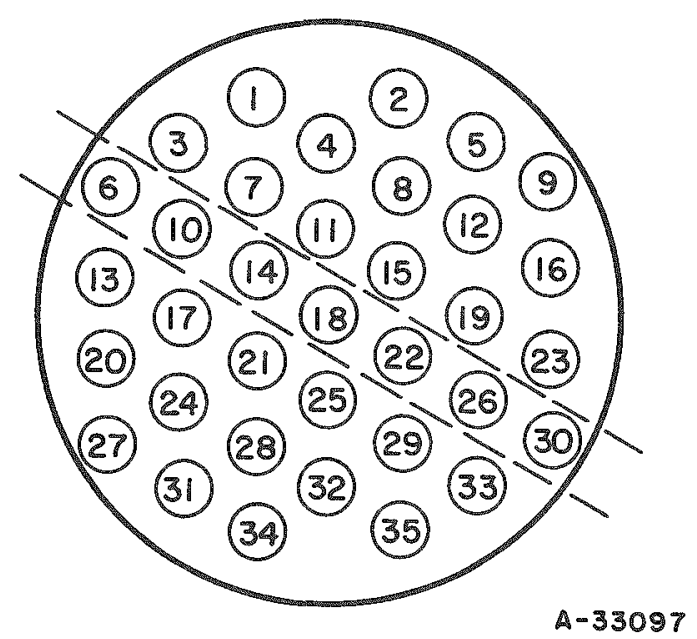

Primary Tube-Sheet Face - Inlet End

FIGURE 5. SYSTEM FOR NUMBERING TUBES IN NONREGENERA TIVE HEAT EXCHANGER

Tube-sheet drain is at the bottom.

Tubes within the diagonal lines were examined. 
TABLE 1. CITRIC ACID-DISODIUM EDTA PROCESS FOR DECONTAMINATING RADIOACTIVE NUCLEAR POWER-PLANT COMPONENTS [MIL-STD-711 (SHIPS), MAX 8, 1959 ]

\begin{tabular}{ll}
\hline \hline Conditions & Amount \\
\hline Solution composition & \\
$\begin{array}{ll}\text { Disodium EDTA } \\
\text { Citric acid } \\
\text { Detergent }\end{array}$ & 1 oz per gal \\
pH (adjusted with NaOH) & 1 oz per gal \\
& 1 oz per gal \\
Temperature & 3.0 to 4.5 \\
Time & 160 to $200 \mathrm{~F}$ \\
\hline \hline
\end{tabular}

(a) Disodium ethylenediaminetetracetate.

Radioactivity on all components was reduced to less than $10 \mathrm{mr}$ per hr using this procedure.

Descaling

All components in contact with the secondary water (fresh water) were covered with a deposit. This deposit dissolved readily in a $1: 1$ solution of concentrated nitric acid and water. The metal beneath the deposit exhibited a bright metallic luster. The surfaces of the heat exchanger which were in contact with the primary water were free of corrosion scale and also exhibited a metallic luster.

Selected portions of the heat exchanger were also subjected to a macroetch to enlarge cracks and make them visible under low-power visual examination. The specimens were immersed $15 \mathrm{~min}$ at $150 \mathrm{~F}$ in the following aqueous solution:

\footnotetext{
Amount, volume per cent

Concentrated hydrochloxic acid 38

Concentrated sulfuric acid

12

Control U-bend specimens of Type 347 stainless steel were included with each macroetching operation. The absence of cracks in these highly stressed samples indicated
} that the macroetch solution did not initiate stress cracking. 
Evaluation

The entire surface of each component was examined visually at 20 diameters of magnification before and after descaling. In addition, dye-penetrant examinations were made of the entire length of the exposed tubes and of the seal welds.

Metallographic sections were made of selected components. Cross sections were made to intersect the surface direction of the cracks at right angles, i.e., transverse sections were made for longitudinal cracks and diagonal sections for circumferential cracks. The length of all cracks and distance from the cut surface were measured to the nearest $0.01 \mathrm{in}$. prior to mounting for metallographic examination. The over-all thickness of the metallographic buttons also was measured to the nearest 0.01 in. Thus the position of all cracks was known with respect to their distance from the ground surface of the button. Each button was reground several times to expose different planes of the crack and thus determine its maximum depth and general appearance.

Metallographic specimens were etched with Kalling's reagent, which contains the following proportions of ingredients: $100 \mathrm{ml}$ of hydrochloric acid, $5 \mathrm{~g}$ of cupric chloride, and $100 \mathrm{ml}$ of ethyl alcohol.

\section{Results}

Seven tubes were selected for examination as shown in Figure 5. The tubes selected were $6,10,14,18,22,26$, and 30 . The corresponding tube stubs remaining in the tube sheet and the tube-sheet segments also were examined. All of the primary-face seal welds were examined. Three baffle plates - one from either end and one from the middle - also were included in the study.

General Appearance of Areas Examined

Seal Welds. The general appearance of the primary-face seal welds at the inlet and outlet ends is shown in the photographs in Figure 6. Visual examination without magnification revealed a very thin brown to olive-green-colored deposit on the surfaces. This deposit was easily removed by wiping, revealing a dull metallic lustex beneath. There was no evidence of corrosion or a tarnish film on the primary-face seal welds.

Tube Sheets in Drain Area. The appearance of the tube sheets in the tube-sheet drain area is shown in the photographs in Figures 7 and 8 . Red rust was detected on the tube sheets at the inlet end. The rust was more evident on the inner tube sheet and appeared to be a result of seepage around the expanded tubes. Rust on the outer tube sheet was confined to the bottom portion and may have been deposited from water standing in the drain. No rust was detected on the tube sheets in the drain area at the outlet end. However, the surfaces of both the inner and outer tube sheets were covered with a tarnish film. The tarnish film probably was present before the heat exchanger was operated since the temperature at the outlet end was not sufficiently high to cause tarnishing of the stainless steel from water vapor or air in the tube-sheet drain area. 


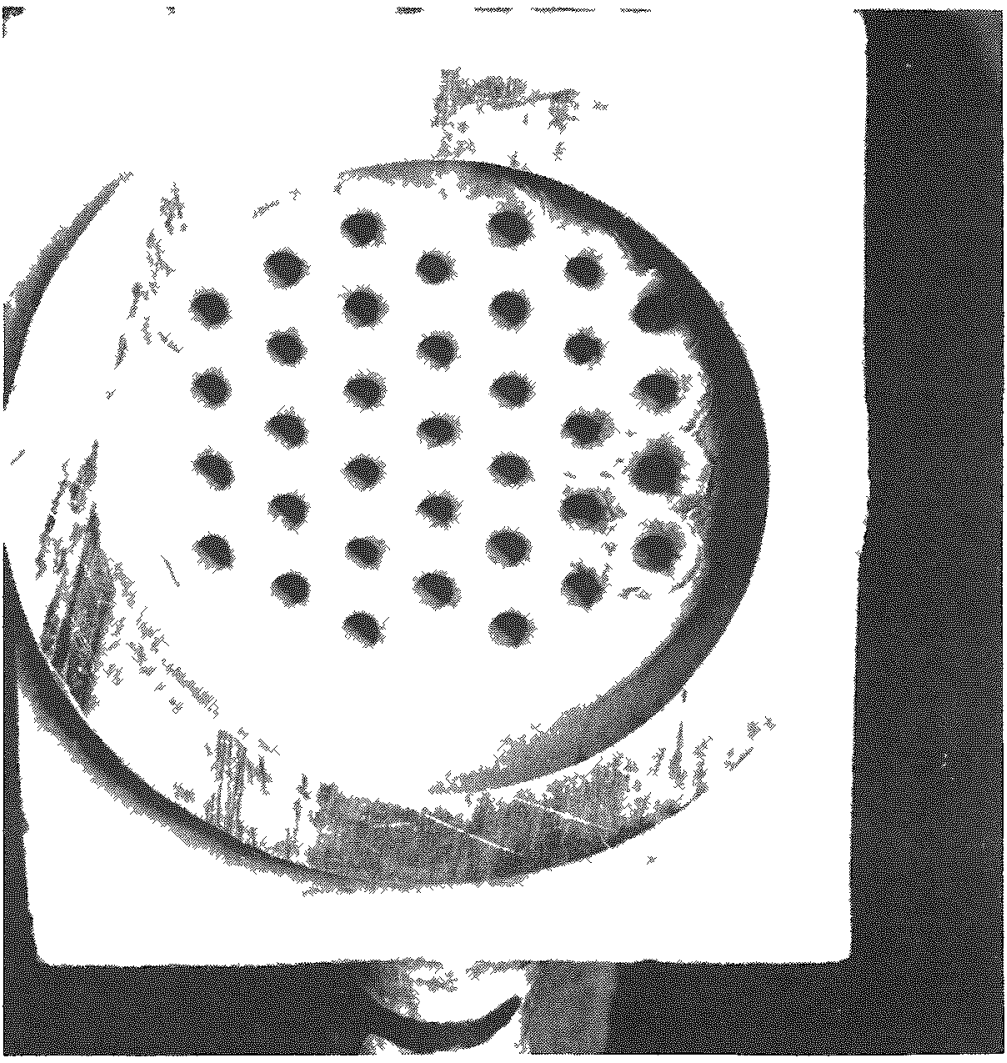

Inlet End

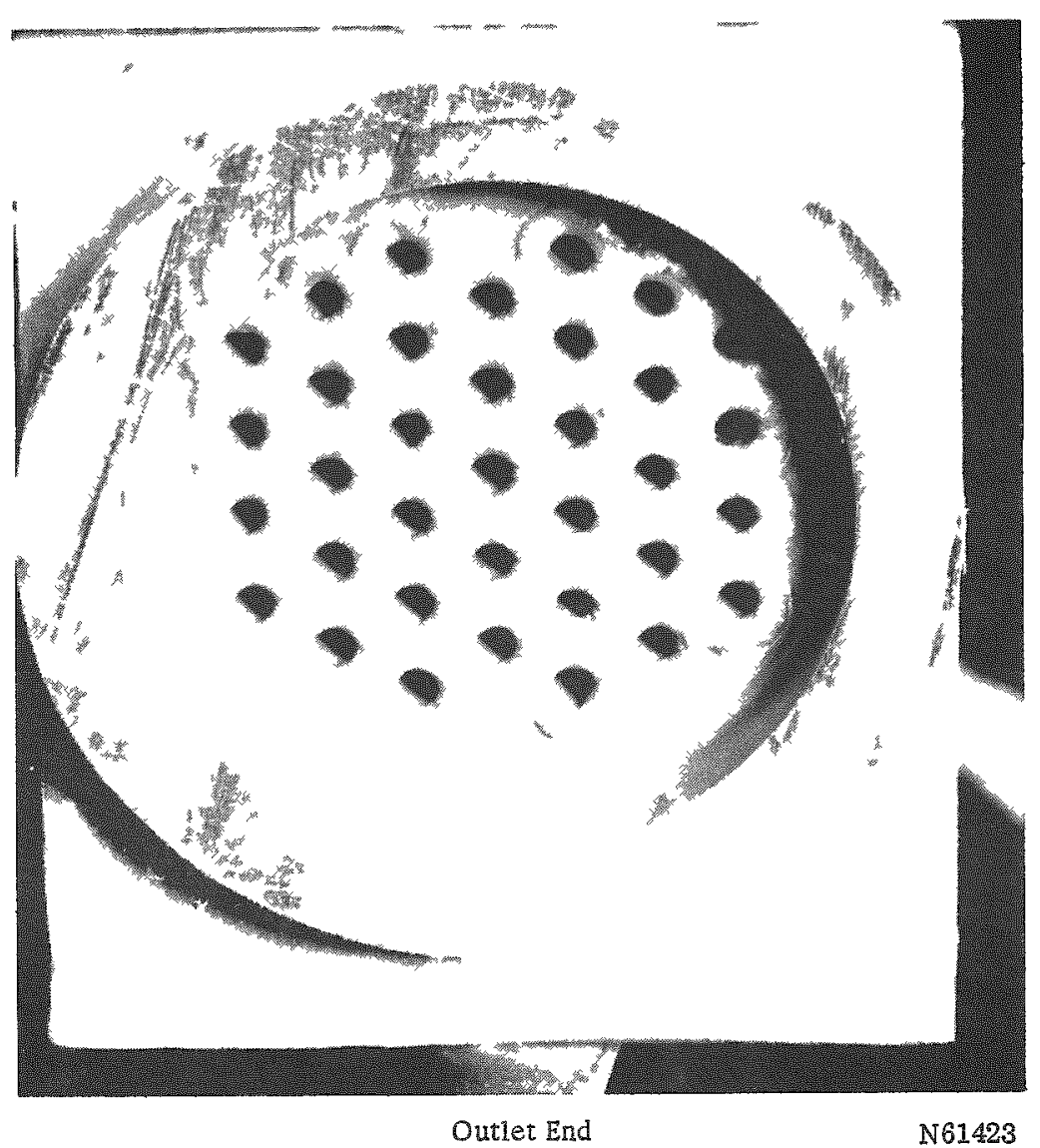

FIGURE 6. APPEARANCE OF PRIMARY -FACE SEAL WELDS IN THE NONREGENERATIVE HEAT EXCHANGER

The tube-sheet drain connection is at the bottom. 

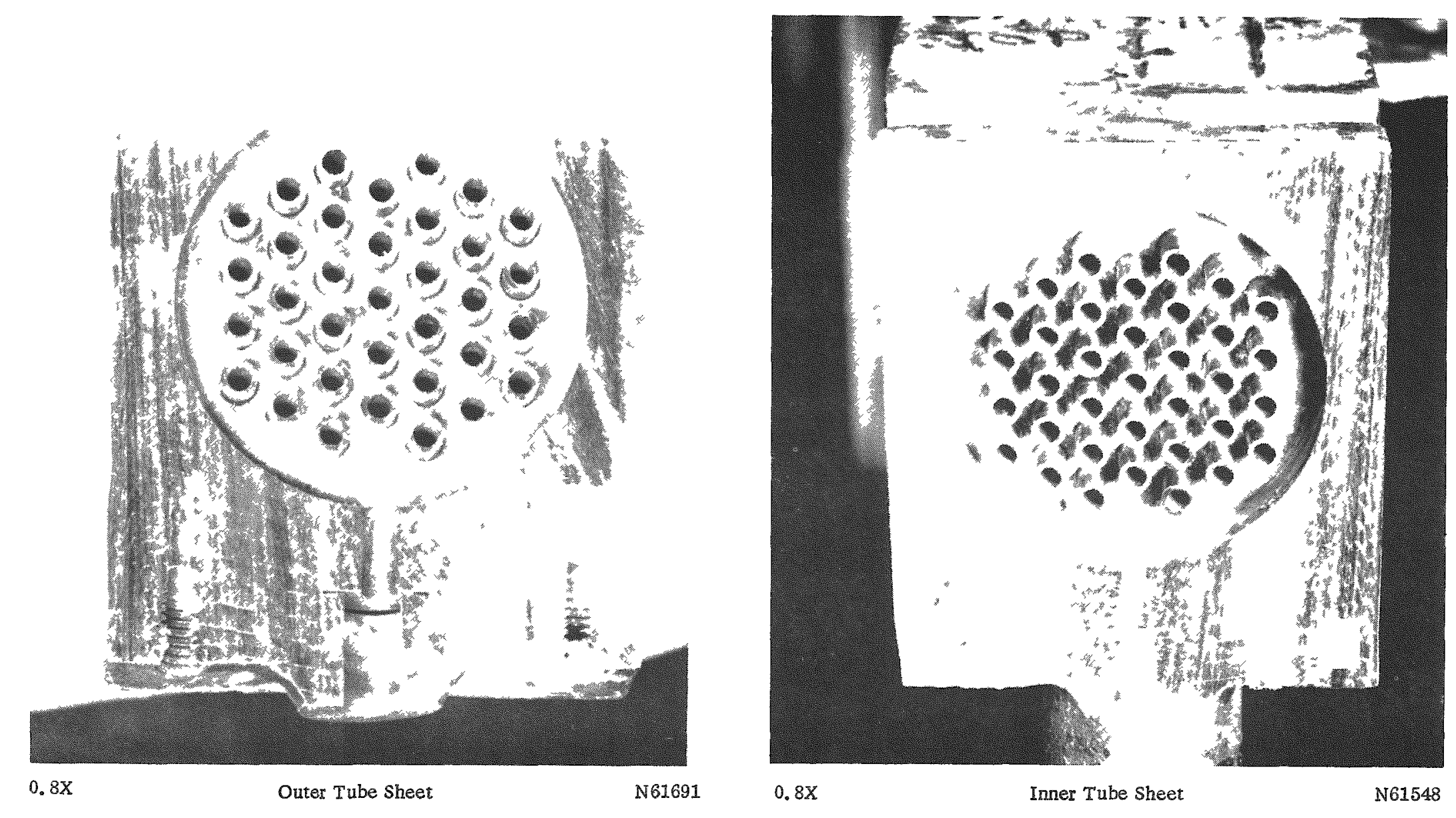

FIGURE 7. APPEARANCE OF THE TUBE SHEET IN THE TUBE-SHEET DRAIN AT THE INLET END OF THE NONREGENERATIVE HEAT EXCHANGER Tube-sheet drain opening is at bottom. Stains on the tube-sheet surface are zust. 


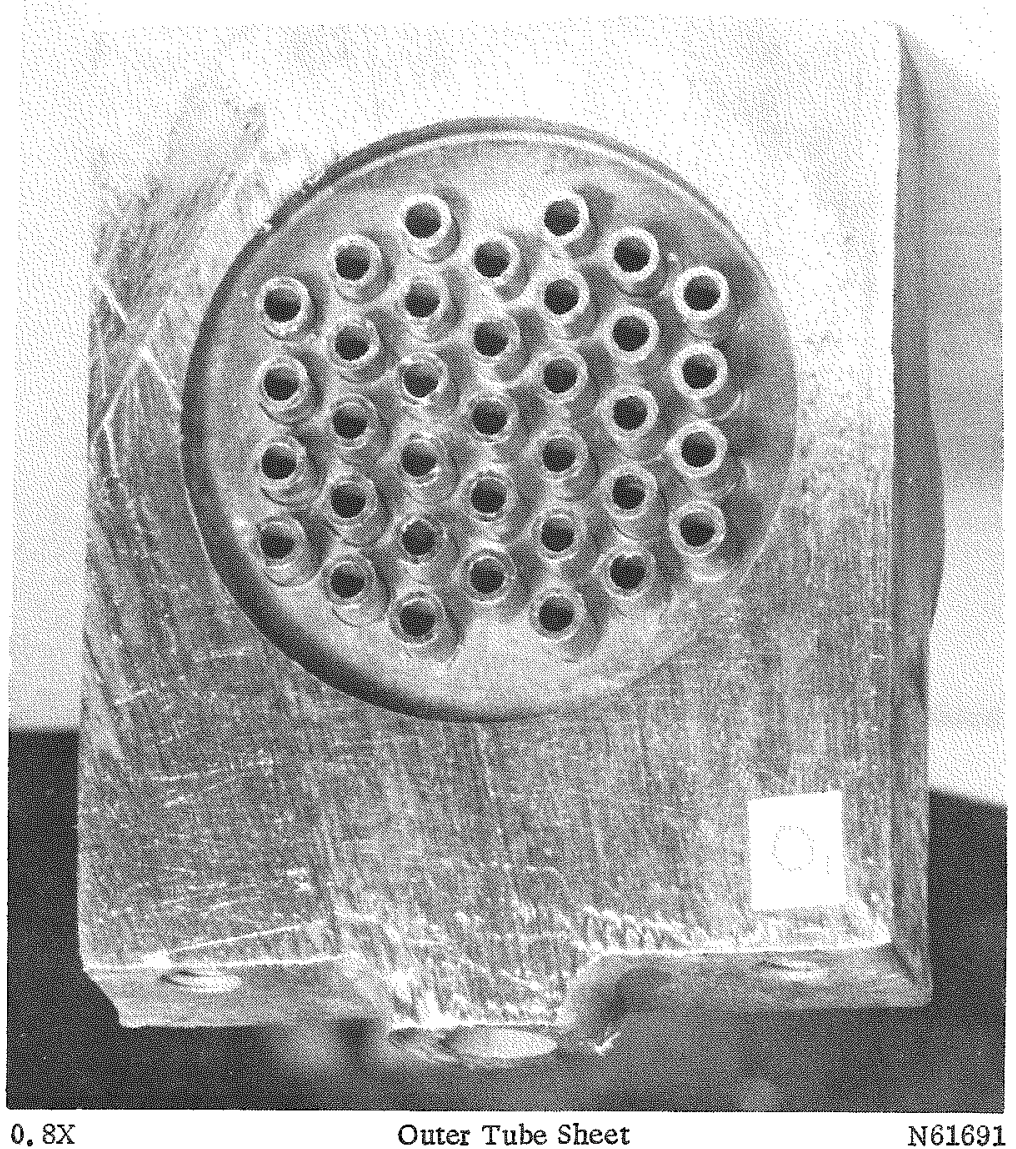

$0.8 \mathrm{X}$

Outer Tube Sheet

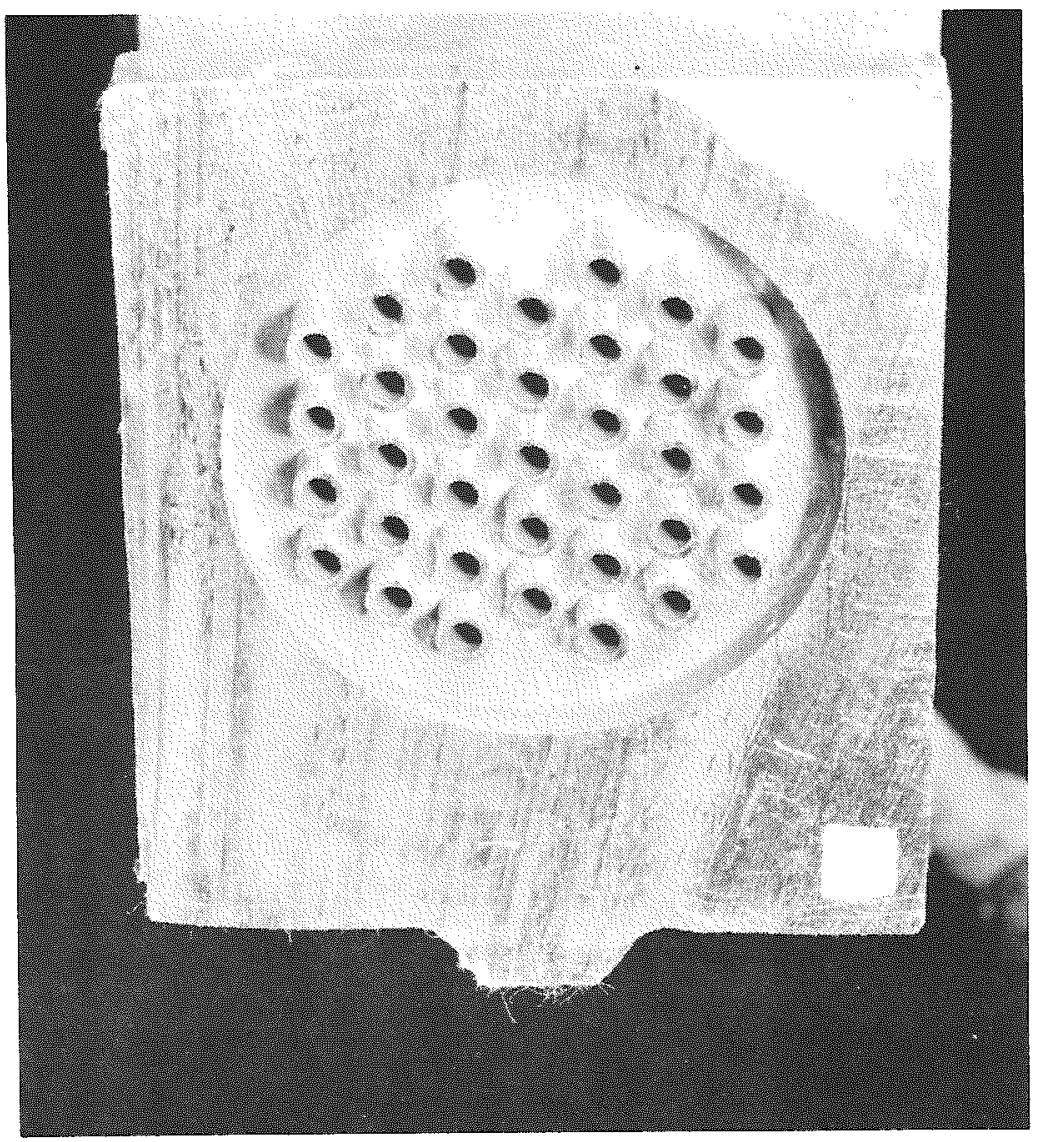

Inner Tube Sheet

Tube-sheet drain opening is at bottom. 
Tube Sheets Contacting Secondary Water. The appearance of tube sheets in conlact with the secondary water is shown in Figure 9. The tube sheet and tube stubs at the inlet end were covered with a thick greenish-black-colored scale. This scale readily laked off, revealing a surface with a metallic luster beneath it. The tube sheet and tube stubs at the outlet end were covered with a thin, powdery, tan deposit which was easily wiped off. The components exhibited a metallic luster beneath the tan deposit. (The composition of these scales is given in the next section.)

Exposed Tubing. The appearance of the secondary surface (outside) of the tubing within the heat exchanger is shown in Figure 10. The tubes were covered with the flaky dark scale at the inlet end and with the powdery, tan deposit at the outlet end. When removed from the she11, the tubes had the appearance shown in Figure 11. About the first $30 \mathrm{in.}$ of the tubes at the inlet end was covered with the flaky dark scale, and the tubes were twisted as shown in the close-up in Figure 12. The remainder of the tubing was straight and was covered with the powdery, tan film. The tan film also was observed on the baffle plates, tie rods, and the inside of the shell regardless of location within the heat exchanger. Thus, the dark scale appeared to be associated with heattransfer surfaces.

Analyses were obtained on samples of the dark scale and the tan deposit. The results are presented in Table 2. It can be seen that the principal component was copper, which ranged from 60 to $90 \mathrm{w} / 0$ in the dark scale and from 10 to $40 \mathrm{w} / 0$ in the tan deposit. The remainder of the dark scale contained from 0.2 to $3 \mathrm{w} / \mathrm{o}$ of iron, lead, nickel, silicon, or zinc and lesser amounts of other metallic ions. Analysis for anion constituents revealed $0.1 \mathrm{w} / 0$ chloride, $2.7 \mathrm{w} / 0$ carbonate, and less than $0.5 \mathrm{w} / 0$ sulfate. The tan deposit contained more calcium, magnesium, and sodium, up to $10 \mathrm{w} / 0$ zinc and silicon, and up to $25 \mathrm{w} / 0$ iron (the latter was probably responsible for the tan color). The tan scale also contained $0.1 \mathrm{w} / 0$ chloride, but less than $0.5 \mathrm{w} / 0$ carbonate and sulfate. The results of the analysis indicate that the scale was salt deposited from the fresh water. The copper probably was picked up from the copper-nickel fresh water-sea. water heat exchangers. The $0.1 \mathrm{w} / 0(1000 \mathrm{ppm})$ chloride found in both scales represents considerable concentration above the 5 ppm (average) in the fresh-water coolant.

\section{Fully Exposed Tubes}

The entire 16-ft length of the seven fully exposed tubes was examined visually at 20 diameters of magnification prior to and after descaling. The entire surface of each tube was also examined with dye penetrant. A large number of indications were obtained with the dye penetrant which were attributable to scratches, indentations, and other obvious surface defects. However, none of the indications seeped or enlarged upon standing as is customary with deep cracks, fissures, or pits. In addition, the first $30 \mathrm{in.}$ (twisted portion) of each tube was macroetched and re-examined at 20 diameters of magnification.

The results of the visual examination are summaxized in Table 3 . Because of the heavy deposit, it was impossible to detect any defects before descaling. Suspected cracks were found on all seven tubes after descaling. Photographs of typical. indications are shown in Figure 13. Long, oval-shaped surface defects, such as that shown in Figure 13, were found on many of the tubes. 


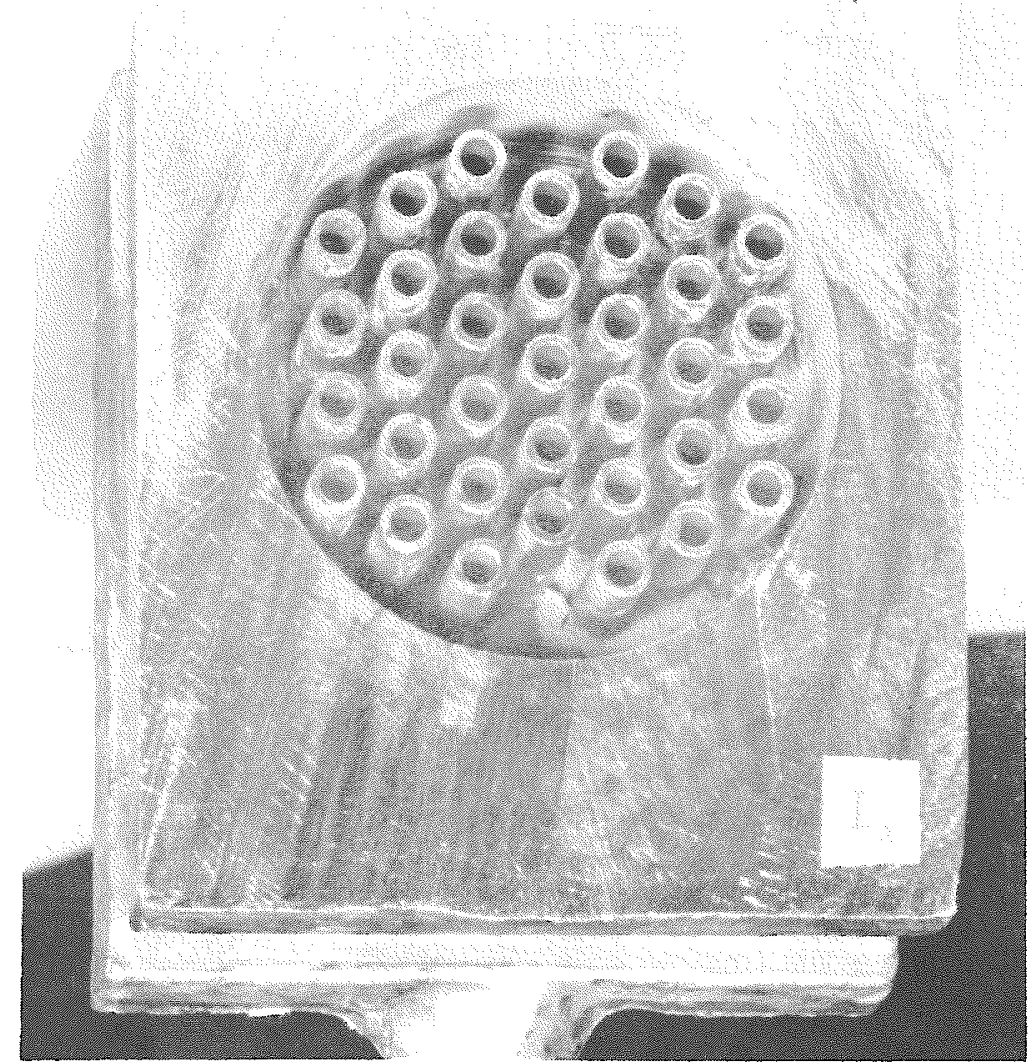

$0.8 \mathrm{X}$
Inlet End

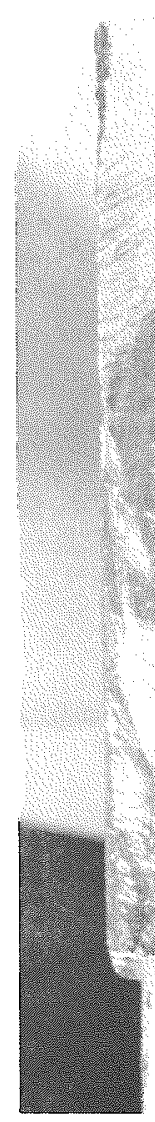

$0.8 \mathrm{X}$

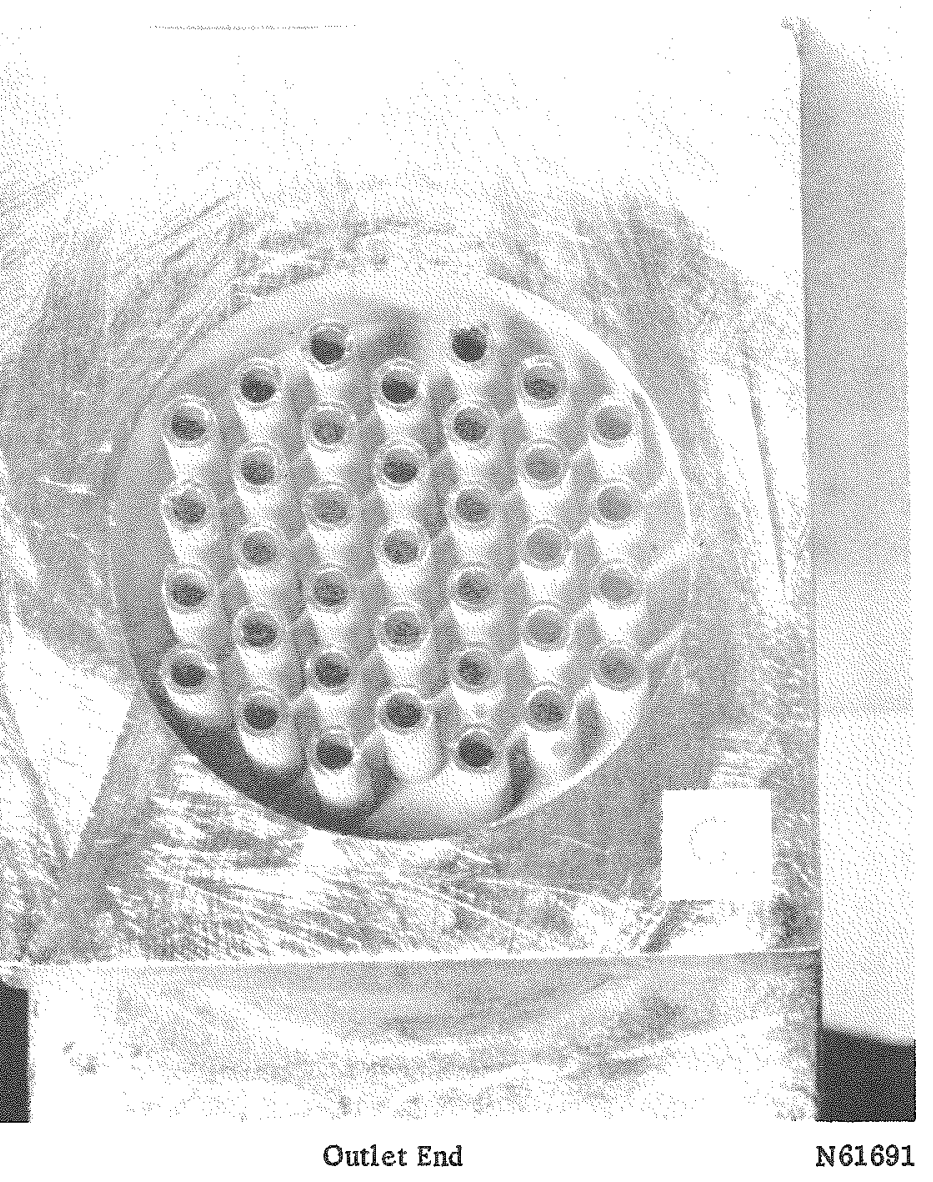

FIGURE 9. APPEARANCE OF INNER TUBE SHEETS IN CONTACT WTTH SECONDARY WATER

The tube-sheet drain is at bottom. Note flaky dark scale on tubes at inler end and smooth uniform light scale on tubes at outlet end. 

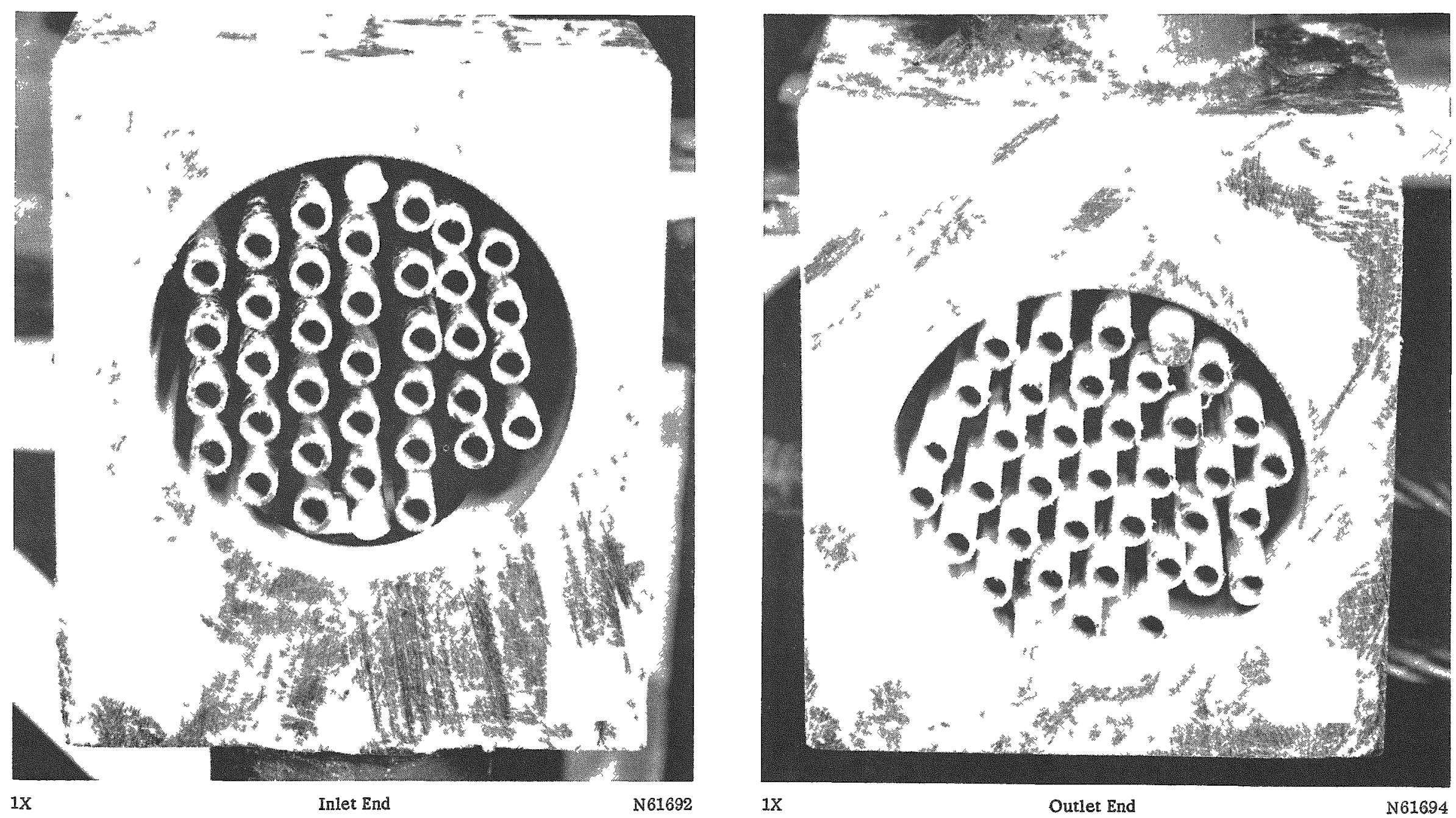

FIGURE 10. APPEARANCE OF TUBES WITHIN THE SHELL IN THE NONREGENERATIVE HEAT EXCHANGER

Tube-sheet dran is at bottom. Solnd bars are baffle-plate tie rods. Note flaky dark scale at inlet end and unform light-colored scale at outlet end. 


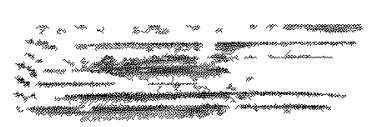

FIGURE 11. APPEARANCE OF ENTIRE LENGTH OF TUBES FROM THE NONREGENERATIVE HEAT EXCHANGER

The inlet end is at left, and the outlet end is toward the right. Note flaky dark scale and twisted tubes at inlet end. 
TABLE 2. ANALYSIS OF DEPOSITS ON TUBES FROM THE NONREGENERA TIVE HEAT EXCHANGER

\begin{tabular}{|c|c|c|}
\hline \multirow[b]{2}{*}{ Element } & \multicolumn{2}{|c|}{ Amount, $w / 0$} \\
\hline & Green-Black Scale & Tan Deposit \\
\hline \multicolumn{3}{|c|}{ Spectrographic Determination } \\
\hline $\mathrm{Ca}$ & $<0,001$ & $0.3-3.0$ \\
\hline $\mathrm{Cu}$ & $60-90$ & $10-40$ \\
\hline $\mathrm{Mg}$ & $<0.001$ & $0.2-2.0$ \\
\hline $\mathrm{Na}$ & $<0,005$ & I. $0-6.0$ \\
\hline $\mathrm{Fe}$ & $0.2=2.0$ & $5-25$ \\
\hline $\mathbb{N i}$ & $0.3-3.0$ & $0.3-3.0$ \\
\hline $\mathrm{Zn}$ & $0.3-3.0$ & $1-10$ \\
\hline Si & $0.2 \sim 2.0$ & $1-10$ \\
\hline $\mathrm{Mn}$ & $0.03-0.3$ & $<0.1$ \\
\hline $\mathrm{Cr}$ & $<0.01$ & $0.2-2.0$ \\
\hline $\mathrm{Pb}$ & $0.2-2.0$ & $0.3-3.0$ \\
\hline sn & $<0.05$ & $0.01-0.2$ \\
\hline Al & $0.02-0.2$ & $0.2-2.0$ \\
\hline $\mathrm{Hg}$ & $0.05-0.15$ & $0.15=0.45$ \\
\hline \multicolumn{3}{|c|}{ Wet Analysis } \\
\hline $\mathrm{Cl}^{\infty}$ & 0.1 & 0.1 \\
\hline $\mathrm{CO}_{3}=$ & 2.7 & $<0.5$ \\
\hline $\mathrm{SO}_{4}=$ & $<0.5$ & $<0.5$ \\
\hline
\end{tabular}


TABLE 3. RESULTS OF EXAMINATIONS OF FULLY EXPOSED TUBES FROM THE NONREGENERATIVE HEAT EXCHANGER

\begin{tabular}{|c|c|c|}
\hline Tube & $\begin{array}{c}\text { Possible Cracked } \\
\text { Areas Observed at } 20 \text { Diameters } \\
\text { of Magnification }(a, b)\end{array}$ & Results of Metallographic Examination \\
\hline \multirow[t]{3}{*}{6} & $4-1 / 8-8: 00^{(c)}$ & $\begin{array}{l}\text { Transverse section; no cracks; three grooves. } \\
\text { Inaximum depth: } 0.5 \text { mil }\end{array}$ \\
\hline & $4-5 / 8-8: 00(c)$ & $\begin{array}{l}\text { Transverse section; no cracks; three grooves, } \\
\text { maximum depth: } 0.5 \mathrm{mil}\end{array}$ \\
\hline & $58-3 / 8-10: 00$ & $\begin{array}{l}\text { Transverse section; no cracks; sufface defect, } \\
\text { maximum depth: 2.0 mils }\end{array}$ \\
\hline \multirow[t]{8}{*}{10} & $36-1 / 2-12: 30$ & Transverse section; no cracks or pits \\
\hline & $49-1 / 4-1: 00$ & Not examined \\
\hline & $55-5 / 8$ to $56-3 / 8-8: 00$ & Not examined \\
\hline & $71-3 / 16-9: 00$ & Not examined \\
\hline & $122-6: 00$ & Not examined \\
\hline & $146-1 / 2-9: 00$ & Not examined \\
\hline & $185-1 / 8$ to $186-3 / 16-12: 00$ & $\begin{array}{l}\text { Transverse section; no cracks; two grooves, } \\
\text { maximum depth: } 0.5 \text { mil }\end{array}$ \\
\hline & No indication & $\begin{array}{l}\text { Random transverse section, } 162-1 / 2 \text {; no } \\
\text { cracks or pits }\end{array}$ \\
\hline \multirow[t]{4}{*}{14} & $37-1 / 16-8: 00^{(d)}$ & Transverse section; no cracks or pits \\
\hline & $45-1 / 4-10: 00$ & $\begin{array}{l}\text { Transverse section; no cracks; one } V \text {-shaped } \\
\text { groove, maximum depth: } 1.0 \mathrm{mil}\end{array}$ \\
\hline & $141-1 / 2-3: 00$ & Not examined \\
\hline & No indication & $\begin{array}{l}\text { Random transperse section; } 185-3 / 4 ; 120 \\
\text { cracks or pits }\end{array}$ \\
\hline \multirow[t]{12}{*}{18} & $13-3 / 4-6: 00(c)$ & Not examined \\
\hline & $35-3 / 8-1: 00$ & Not examined \\
\hline & $64-1 / 8-3: 00^{(d)}$ & $\begin{array}{l}\text { Transverse section; no cracks; groove, } \\
\text { maximum depth: } 0.5 \mathrm{mil}\end{array}$ \\
\hline & $113-15 / 16-3: 00$ & Not examined \\
\hline & $124-7 / 8-8: 00$ & Transverse section; no cracks or pits \\
\hline & $134-7 / 8-10: 00$ & Not examined \\
\hline & $153-3 / 4-5: 00$ & Not examined \\
\hline & $166-1 / 8$ to $170-11: 00(\mathrm{~d})$ & $\begin{array}{l}\text { Transverse section; no cracks; cold shut, } \\
\text { maximum depth: } 2.0 \text { mils }\end{array}$ \\
\hline & $171-13 / 16$ to $173-3 / 8-12: 00$ & Nol examined \\
\hline & $173-3 / 4-12: 00$ & Not examined \\
\hline & $176-3 / 4$ to $177-7 / 16-12: 00$ & Not examined \\
\hline & $191-7 / 16-4: 00^{(d)}$ & $\begin{array}{l}\text { Transverse section; no cracks, large gonge, } \\
\text { maximum depth: } 3 \text { mils }\end{array}$ \\
\hline \multirow[t]{4}{*}{22} & $34-3 / 8-12: 00$ & Not examined \\
\hline & $57-1 / 8-12 ; 00$ & Transverse section; no cracks or pits \\
\hline & $137-5 / 8-8: 00$ & $\begin{array}{l}\text { Transverse section; no cracks; grooves, } \\
\text { maximum depth: } 1.0 \mathrm{mil}\end{array}$ \\
\hline & No indication & $\begin{array}{l}\text { Randoin transwerse section; } 140-1 / 4 \text {; no } \\
\text { cracks or pirs }\end{array}$ \\
\hline
\end{tabular}


TABLE 3。 (Continued)

\begin{tabular}{|c|c|c|}
\hline Tube & $\begin{array}{c}\text { Possible Cracked } \\
\text { Areas Observed at } 20 \text { Diameters } \\
\text { of Magnification }(a, b)\end{array}$ & Results of Metallographic Examination \\
\hline \multirow[t]{6}{*}{26} & $44-11 / 16-9: 00$ & $\begin{array}{l}\text { Transverse section; no cracks; three grooves, } \\
\text { maximum depth: } 0.25 \mathrm{mil}\end{array}$ \\
\hline & $66-5 / 8-5: 00$ & Not examined \\
\hline & $82-13 / 16-7: 00$ & $\begin{array}{l}\text { Transverse section; no cracks; shallow groove, } \\
\text { maximum depth: } 0.5 \mathrm{mil}\end{array}$ \\
\hline & $115-3 / 4-8: 00(d)$ & $\begin{array}{l}\text { Transverse section; straight crack, maximum } \\
\text { depth: } 2.5 \text { mils }\end{array}$ \\
\hline & $119-9 / 16-10: 00$ & Not examined \\
\hline & $181-11 / 16-5: 00$ to $8: 00$ & Not examined \\
\hline \multirow[t]{15}{*}{30} & $11-3 / 4-3: 00$ & Not examined \\
\hline & $18-1 / 8-11: 00(\mathrm{c})$ & Not examined \\
\hline & $19-5 / 8$ to $20-11: 00(c)$ & Not examined \\
\hline & $58-3 / 8-12: 30$ & Diagonal section; no cracks or pits \\
\hline & $59-3 / 4-11: 00$ to $2: 00$ & Not examined \\
\hline & $61-3 / 4-6: 00$ & Not examined \\
\hline & $74-3 / 4-11: 00$ & Not examined \\
\hline & $92-13 / 16-12 ; 00$ & $\begin{array}{l}\text { Transverse section; no cracks; two grooves, } \\
\text { maximum depth: } 0.5 \mathrm{mil}\end{array}$ \\
\hline & $101-1 / 2-9: 00$ & Not examined \\
\hline & $118-9 / 16-6: 00$ & Not examined \\
\hline & $131-3 / 8-8: 30$ & Not examined \\
\hline & $145-3 / 4-2 ; 00$ & Not examined \\
\hline & $175-1 / 16-7: 00$ & $\begin{array}{l}\text { Transverse section, no cracks; shallow groove, } \\
\text { maximum depth: } 0.5 \mathrm{mil}\end{array}$ \\
\hline & $188-7 / 16-7: 00$ & Not examined \\
\hline & $196-1 / 4-8: 00$ & Not examined \\
\hline
\end{tabular}

(a) All crack indications were longitudinal on tubing.

(b) Number indicates distance from seal-weld surface at inlet, and clock designation indicates position on circumference of tube as viewed from inlet end looking toward outlet end.

(c) Indications revealed after macroetching.

(d) Corresponds with a dye-penetrant indication. 

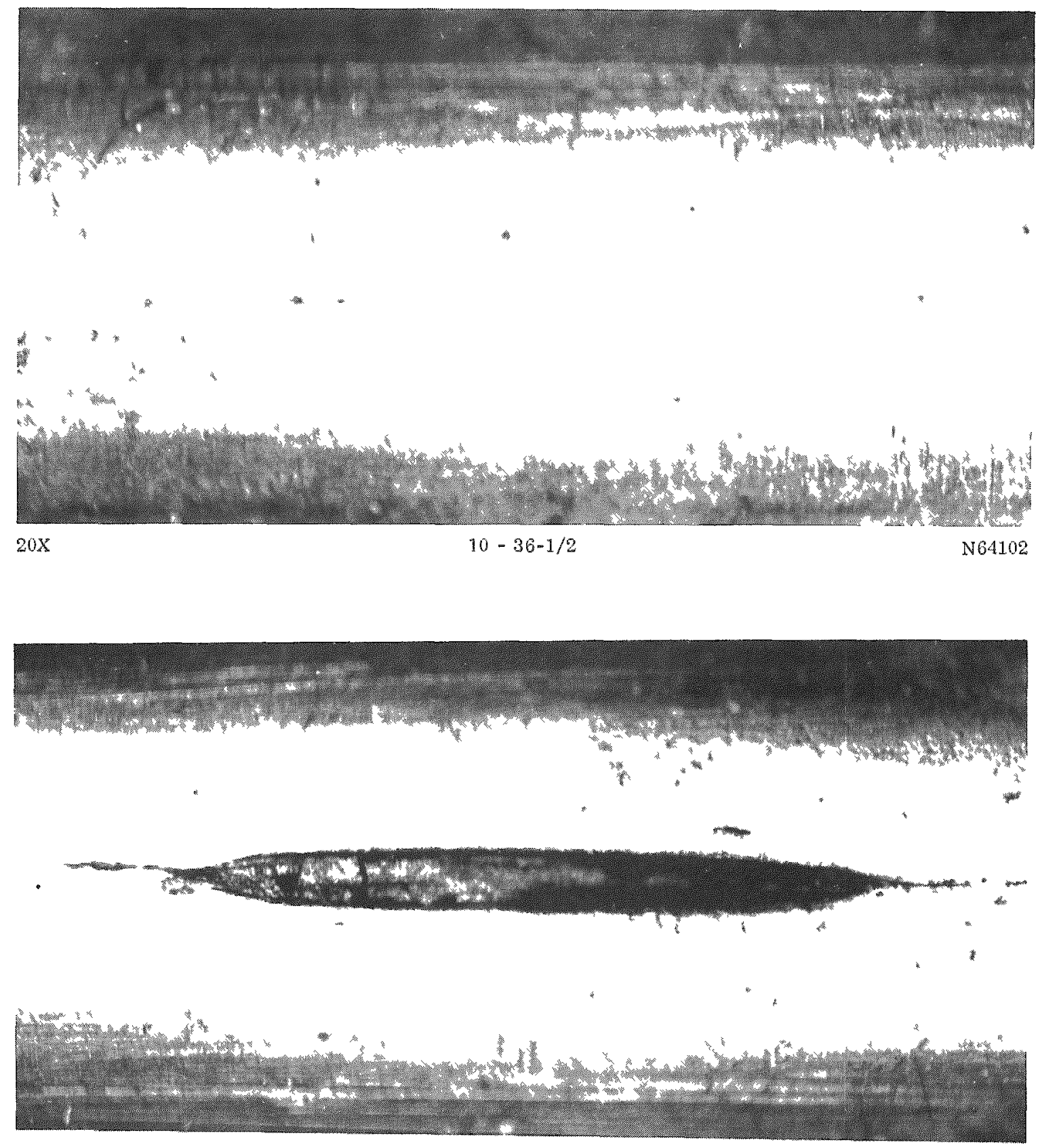

TIGURE 13. SURFACE APPEARANCE OF TI PICAL DEFECTS IN 1 IIE EXPOSED TUBING OF THE NONREGENERATIVE HEAT EXCHANGER

Note cold shut in $26^{\circ}-115-3 / 4$. 
Metallographic cross sections through 3 of the crack indications on each tube (total, 21) revealed only one example of what appeared to be a stress-corrosion crack. This occurred on Tube 26 (115-3/4 in. from the inlet seal weld) and corresponded with the crack extending out of the surface defect shown in Figure 13. A photomicrograph of a cross section of this crack is shown in Figure 14. The crack was straight and shallow (about 2.5 mils deep), but its transgranular nature indicated that it was a stresscorrosion crack.

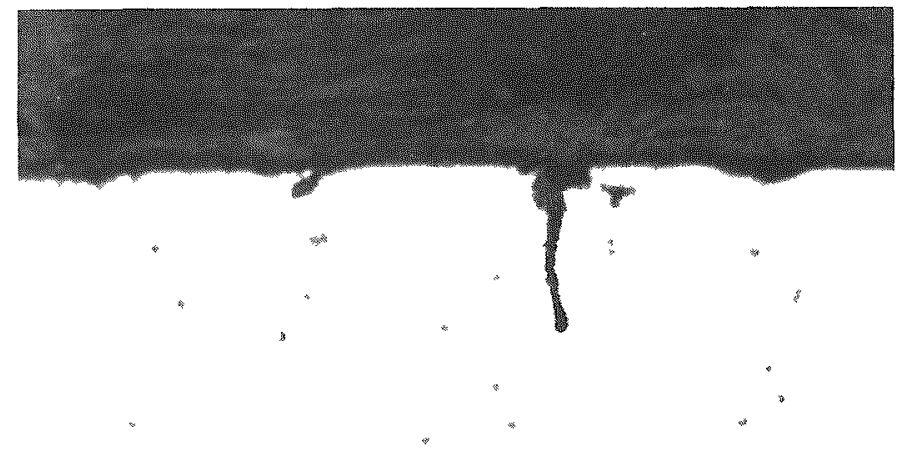

\section{FIGURE 14. PHOTOMICROGRAPH OF CROSS SECTION OF CRACK ASSOCIATED WITH A COLD SHUT IN TUBE 26}

This crack was 115-3/4 in. fxom the inlet primary face. See Figure 13 for surface appearance of crack. A transverse section is shown here.

Cross sections of the other 20 indications examined revealed no cracks, but only surface defects such as scratches, gouges, grooves, and cold shuts. The appearances of typical cross sections of these are illustrated in the photomicrographs in Figure 15. Note the absence of cracking and the smooth appearance of the grooves and the photograph of a cold shut in Figure 1.5 .

\section{Tube Stubs From Tube Sheets}

In general, the tube stubs which were removed from the tube sheets retained their metallic luster. The exceptions were: (1) the $1 / 2-i n$. portion which extended into the secondary water and (2) the appearance of red rust on a smanl area of the tubing at the juncture with the inner tube sheet in the drain area at the inlet end. Apparent cracking was observed on only 3 of the 28 tube stubs examined prior to macroetching. Cracks on two of the tube stubs were located at the tube-to-tube-sheet juncture on the drain side of 

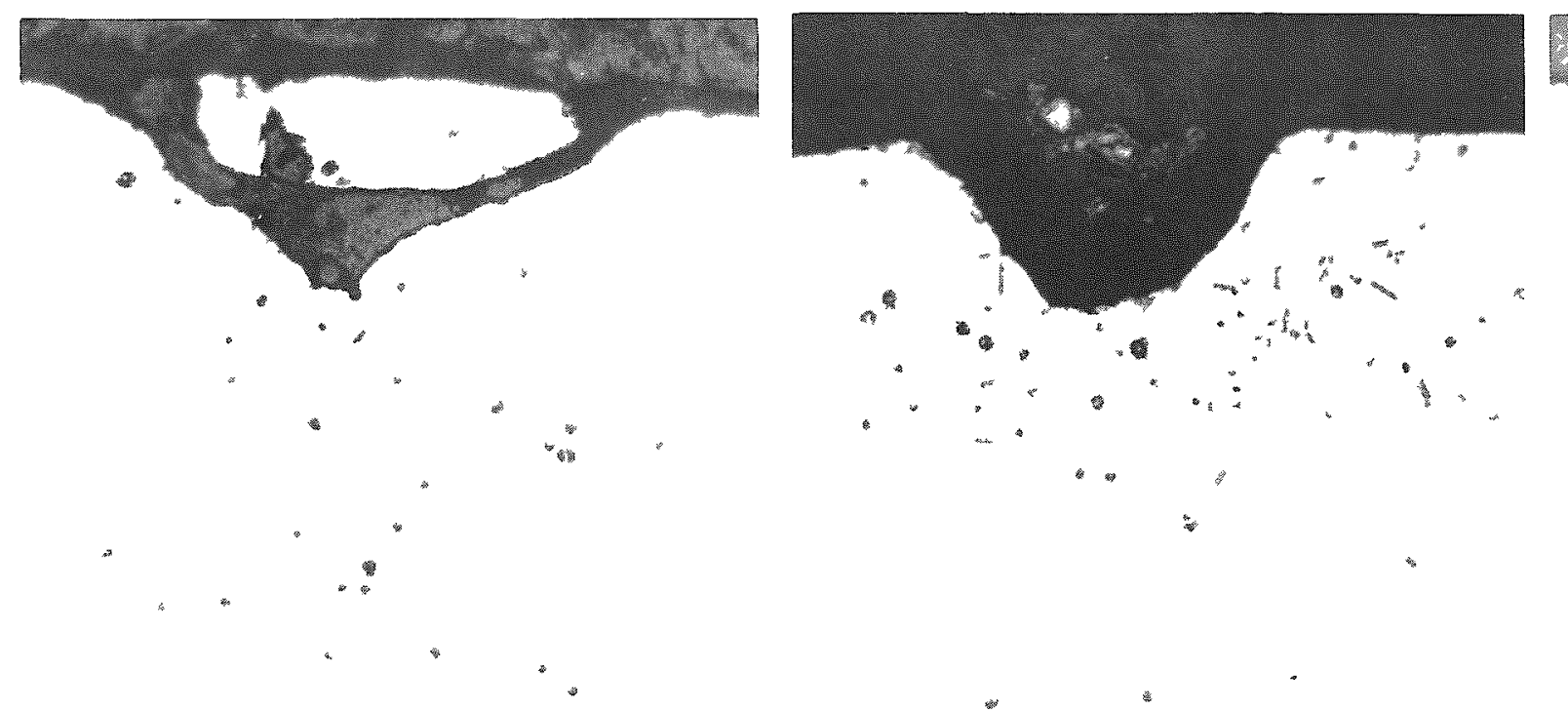

$250 \mathrm{X}$

$18-166-1 / 8$

C867 250X

$18-191-7 / 16$

$\mathrm{C} 819250 \mathrm{X}$

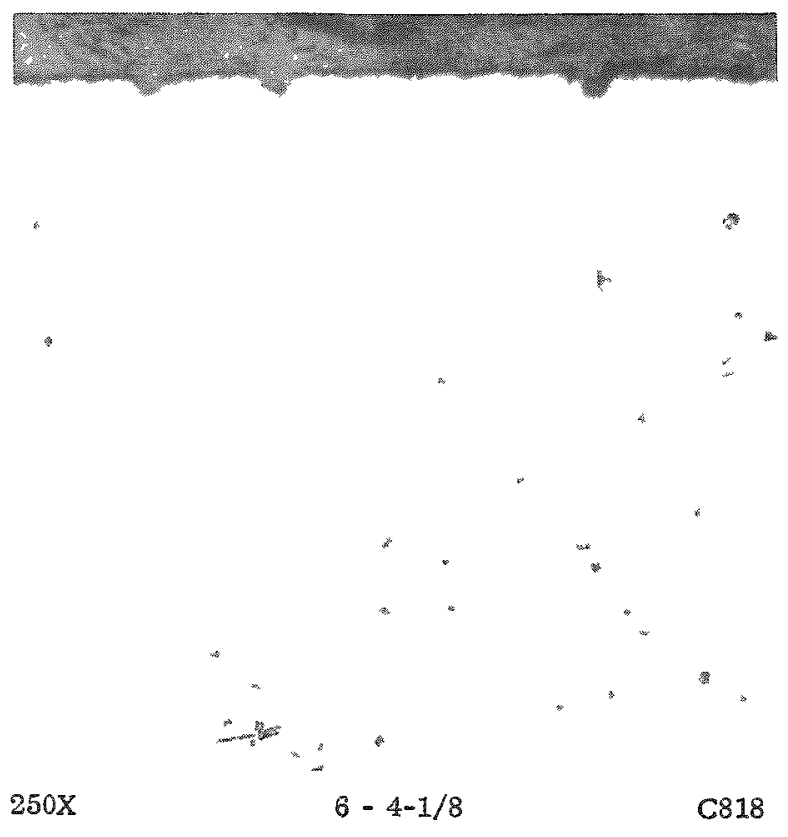

$\mathrm{C} 818$

FIGURE 15. PHOTOMICROGRAPHS OF CROSS SECTIONS THROUGH TYPICAL SURFACE DEFECTS IN THE EXPOSED TUBES OF THE NONREGENERATIVE HEAT EXCHANGER

The cross section of $18-166-1 / 8$ is typical of the cold shut shown in Figure 13. Transverse sections are shown. 
the inner tube sheet at the inlet end, and were surrounded by red rust. The surface appearance of one of these cracks is shown in Figure 16. The other suspected crack was located within the outer tube sheet at the inlet end.

All of the tube stubs were then macroetched. The results of examinations after macroetching are included in Table 4. No additional cracks were observed in the tube stubs from the outer tube sheets at either end. There were crack indications on all seven tubes from the inner tube sheet at the inlet end. Six of the indications were in the drain area at the rube-to-tube sheet juncture, and the seventh was within the tube sheet. The surface direction of cracks ranged from circumferential, to branching, to longitudinal. Crack indications were found on four of the seven tubes from the inner tube sheet at the outlet end. Indications on one tube were located both at the tube-to-tube sheet juncture in the drain area and also within the tube sheet. The indications on the remaining three tubes were within the tube sheet. Additional photographs of the surface appearance of the crack indications in tubes from the inner tube sheets are presented in Figure 17.

Metallographic examinations were conducted at all crack indications. In addition, sections were made at the tube-sheet junctures of four randomly selected tube stubs from each of the outer tube sheets. No cracks were found in the latter.

Cracking was found at the tube-to-tube sheet juncture on the drain side in five of the seven tube stubs from the inner tube sheet at the inlet end. The cracks started on the external surface of the tubing and penctrated toward the inner surface. The cracking was transgranular and generally was branching. Photomicrographs of the cracks are presented in Figures 18, 19, and 20. Note the montage in Figure 18 which represcnts the worst example of cracking that was observed. The cross section was made diagonally across the tubing; this accounts for the apparent thickening of the tubing wall. Maximum penetration of cracks was 28 mils or 80 per cent through the 35 -mil-thick tubing walls.

No cracks were found on Tube Stub 22 from the outer lube sheet at the inlet end. The cross section through the indication observed visually at 20 diameters of magnification revealed what appeared to be a cold shut. A photomicrograph of a cross section through this surface defect is shown in Figure 21 .

No cracks were found in the four suspected tube stubs from the inner tube sheet at the outlet end. Metallographic sections revealed that the indications were surface defects which apptared to be grooves or scratches. The maximum depth of these "grooves" was 1 mil. A photomicrograph of a cross section of a representative groove is presented in Figure 22 .

No cracks or surface defects were found in cross sections of four randomly sclectod tubes sirbs from the outer tube sheet at the outlet end.

Thus, the results of the metallographic examinations confirmed crack indications in only five tube stubs. These were all located in the drain area adjacent to the inner tube sheet at the inlet end where seepage and red rust were observed. All of the other crack indications appeared to be quite similar to the scratches and gouges observed for the fully exposed tubes. 


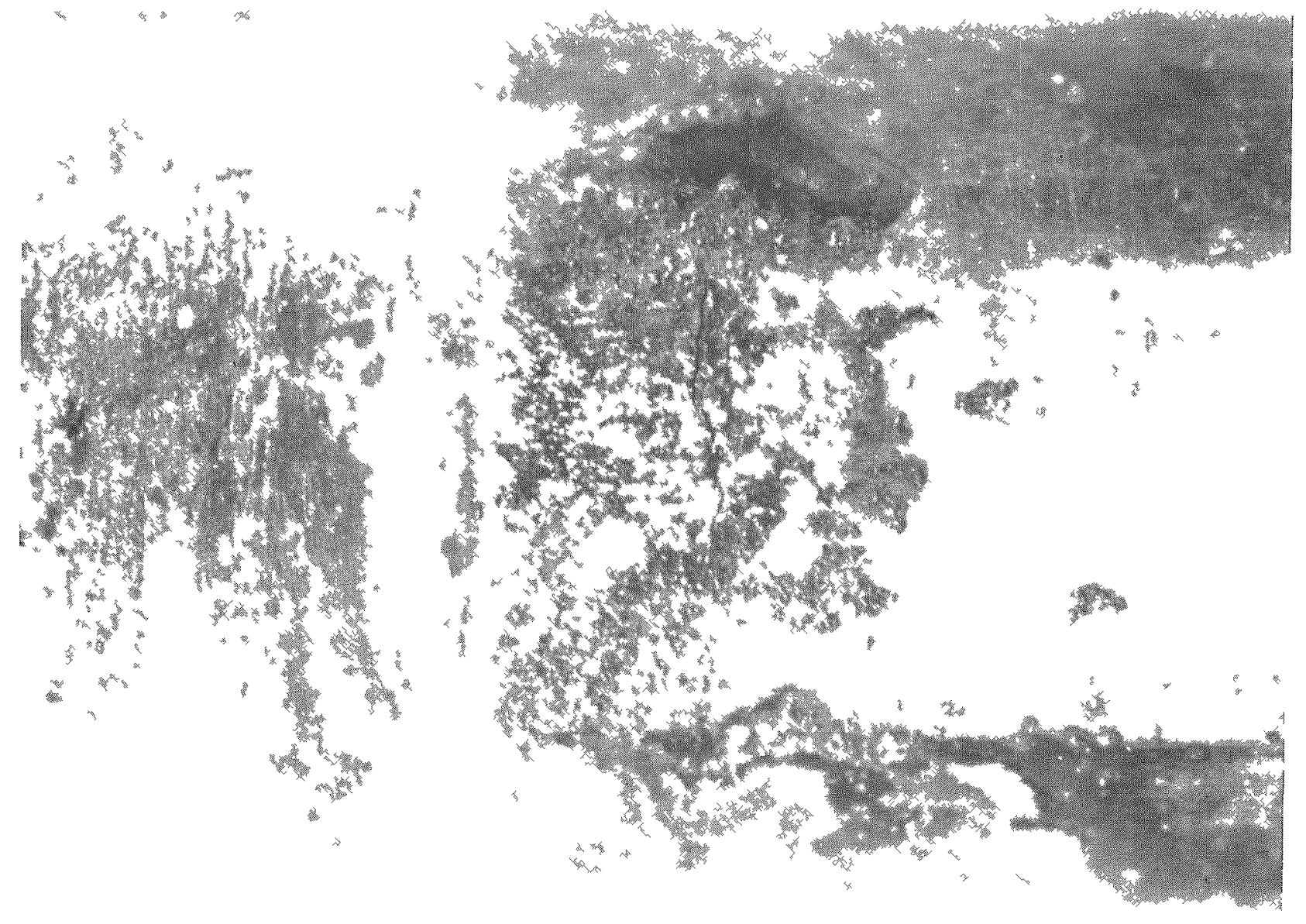

FIGURE 16. SURFACE APPEARANCE OF CRACK IN TUBR STUB 10 AI I HE DRAIN-SIDE SURFAGE OF THE INNER TUBE SHEET AT THE INLET END

Note that corrosion product (rust) surrounds the crack and that the crack is located at an area formed at the very end of the tube-expanding operation. 
TABLE 4. RESULTS OF EXAMINATION OF TUBE STUBS TAKEN FROM TUBE SHEETS IN THE NONREGENERATIVE HEAT EXCHANGER

\begin{tabular}{|c|c|c|c|}
\hline \multirow{2}{*}{$\begin{array}{l}\text { Tube } \\
\text { Stub }\end{array}$} & \multicolumn{2}{|c|}{ Location of Possible Cracks(a) } & \multirow[b]{2}{*}{ Results of Metallographic Examnation } \\
\hline & Before Descaling & After Descaling & \\
\hline \multicolumn{4}{|c|}{ From Outer Tube Sheet at Inlet End } \\
\hline 6 & None & None $(b)$ & Transverse section at tube-sheet juncture, no cracks or pits \\
\hline 10 & None & None (b) & Transverse section at tube-sheet juncture; no cracks or pits \\
\hline 14 & None & None (b) & Not examned \\
\hline 18 & None & None $e^{(b)}$ & Transverse section at tube-sheet juncture; no cracks or pits \\
\hline 22 & Within tube sheet & Longitudinai cracks at $12: 30$ & Transverse section through cold shut on tube surface, no cracks or pirs \\
\hline 26 & None & Nonel $(b)$ & Not examined \\
\hline 30 & None & None(b) & Transverse section at tube-sheet juncture, no cracks or pits \\
\hline \multicolumn{4}{|c|}{ From Inner Tube Sheet at Inlet End } \\
\hline 6 & None & $\begin{array}{l}\text { Circumferential crack within tube sheet near drain area, } \\
4: 00^{\text {(b) }}\end{array}$ & Diagonal section; no cracks; shallow groove, maximum depth: $0.5 \mathrm{mll}$ \\
\hline 10 & In drain area at tube sheet & Curcumferentual crack in drain area, 7:00 & Dragonal section; branching crack, maximum depth: 12 mils \\
\hline 14 & None & Branchng cracks in drain area, 9.00 to $1.00^{(b)}$ & $\begin{array}{l}\text { Diagonal section; branching and straight cracks, maximum depth: } \\
28 \mathrm{mils}\end{array}$ \\
\hline 18 & None & Branching cracks in drain area, $8: 00$ to $12.00^{(b)}$ & Diagonal section; straight crack, maximum depth: $2.5 \mathrm{mils}$ \\
\hline 22 & In drain area at tube sheet & Longitudinal cracks in drain area, $6: 00$ & Diagonal section; branchng crack, maximum depth: 11 mils \\
\hline 26 & None & Dragonal crack in drain area, $2: 00(\mathrm{~b})$ & Diagonal section, no cracks; two grooves, maximum depth: $0.25 \mathrm{mll}$ \\
\hline 30 & None & Curcumferential crack un drain area, $9: 00$ to $11: 00^{(b)}$ & Diagonal section; branching crack, maximum depth: 14 mils \\
\hline \multicolumn{4}{|c|}{ From Inner Tube sheet at Outlet End } \\
\hline 6 & None & None $(b)$ & Not exammed \\
\hline 10 & None & $\begin{array}{l}\text { Longitudinal crack within tube sheet near drain area. } \\
3: 00(b)\end{array}$ & $\begin{array}{l}\text { Diagonal sectıon; no cracks, shallow groove, maximum depth: } \\
0.5 \mathrm{mil}\end{array}$ \\
\hline \multirow[t]{2}{*}{14} & None & Circumferential crack in drain area, $7: 00$ (b) & $\begin{array}{l}\text { Diagonal section; no cracks; shallow groove, maximum depth: } \\
0.5 \mathrm{mil}\end{array}$ \\
\hline & & Long1tudinal cracks withm tube sheet, $8: 00(\mathrm{~b})$ & Transverse section; no cracks; groove, maximum depth: $1.0 \mathrm{mil}$ \\
\hline 18 & None & Longitudinal crack withn tube sheet, $3: 00(\mathrm{~b})$ & $\begin{array}{l}\text { Transverse section; no cracks; shallow groove, maximum depth: } \\
0.25 \mathrm{mil}\end{array}$ \\
\hline 22 & None & Long1tudnnal crack w1thin tube sheet, $3: 00^{(b)}$ & $\begin{array}{l}\text { Transverse section; no cracks, shallow groove, maximum depth: } \\
0.75 \mathrm{mil}\end{array}$ \\
\hline 26 & None & None(b) & Not examned \\
\hline 30 & None & None (b) & Not exammed \\
\hline
\end{tabular}

Longitudinal cra

Dragonal crack in draun area, 2:00(b)

Crrcumferential crack in drain area, $9: 00$ to $11: 00^{(b)}$
Not examined 
TABLE 4. (Continued)

\begin{tabular}{|c|c|c|c|}
\hline \multirow{2}{*}{$\begin{array}{l}\text { Tube } \\
\text { Stub }\end{array}$} & \multicolumn{2}{|c|}{ Location of Possible Cracks(a) } & \multirow[b]{2}{*}{ Results of Metallographic Examination } \\
\hline & Before Descaling & After Descaling & \\
\hline \multicolumn{4}{|c|}{ From Outer Tube Sheet ac Outlet Fnd } \\
\hline 3 & None & None (b) & Transwerse section at tube-sheer juncture; no cracks or pits \\
\hline 10 & None & None ${ }^{(b)}$ & Not examined \\
\hline 14 & None & None(b) & Not examined \\
\hline $1,6^{\circ}$ & None & None (b) & Transverse section at tube-sheet juncture; no cracks or pits \\
\hline 20 & None & None $e^{(b)}$ & Transverse section at tube-sheet juncture; no cracks or pits \\
\hline 20 & None & None ${ }^{(b)}$ & Not examined \\
\hline 30 & None & None (b) & Transverse section at tube-sheet juncture; no cracks or pits \\
\hline
\end{tabular}

(a) C. xck designation indicates position on circumference of tubing as viewed from inlet end looking toward outlet end.

(b) Macroetched in addition to chemical descaling. 

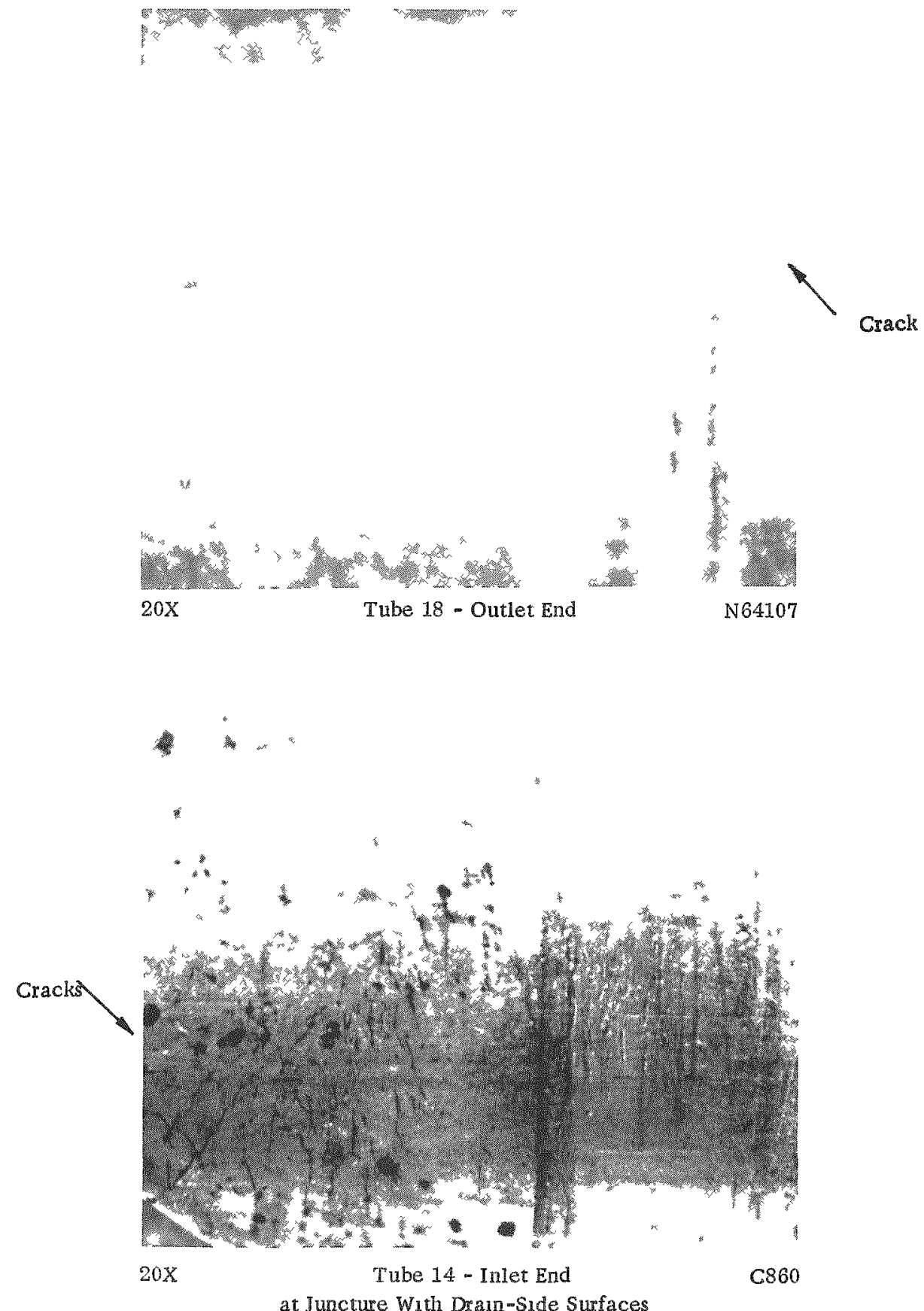

FIGURE 17. SURFACE APPEARANCE OF CRACK INDICATIONS ON TUBE STUBS FROM THE INNER TUBE SHEETS Crack indication in Tube 18 crosses the two vertical grooves which corresponded with serrations in the tube sheet. 


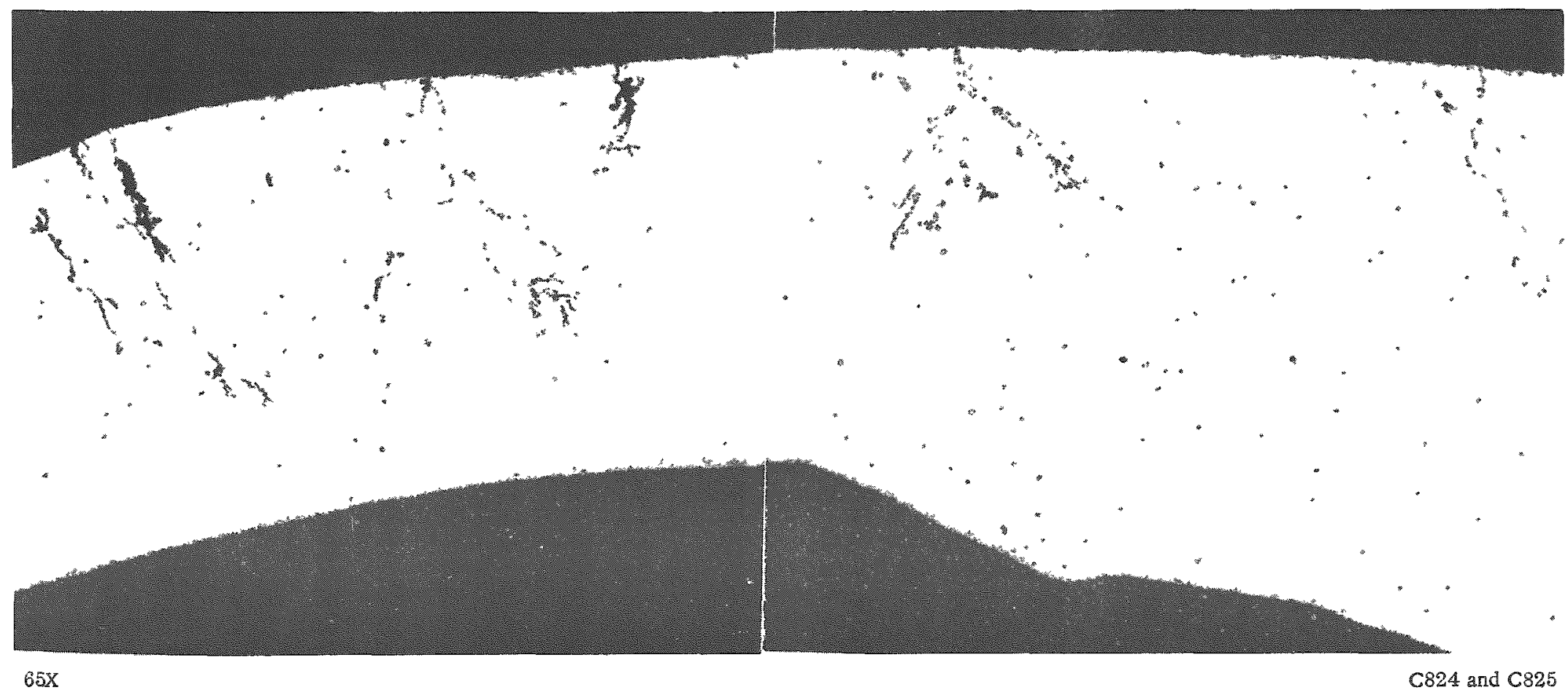

FIGURE 18. MONTAGE OF PHOTOMICROGRAPHS OF CROSS SECTIONS THROUGH TUBE STUB 14 AT THE JUNCTURE WITH THE DRAIN-SIDE SURFACE OF THE INNER TUBE SHEET AT THE INLET END

The section was cut on the diagonal, thus accounting for the apparent thickness increase seen at the right, 

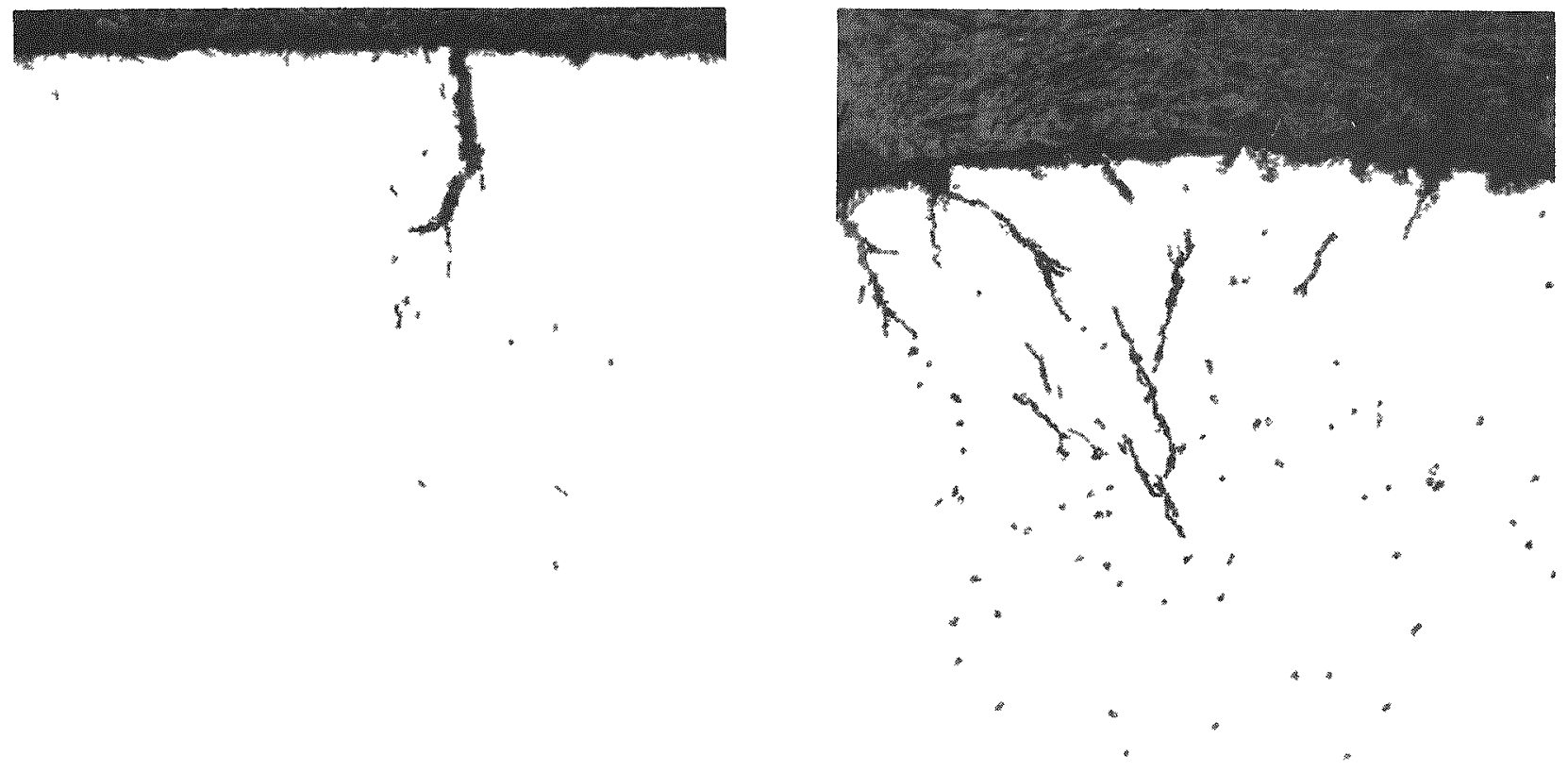

$100 \mathrm{X}$
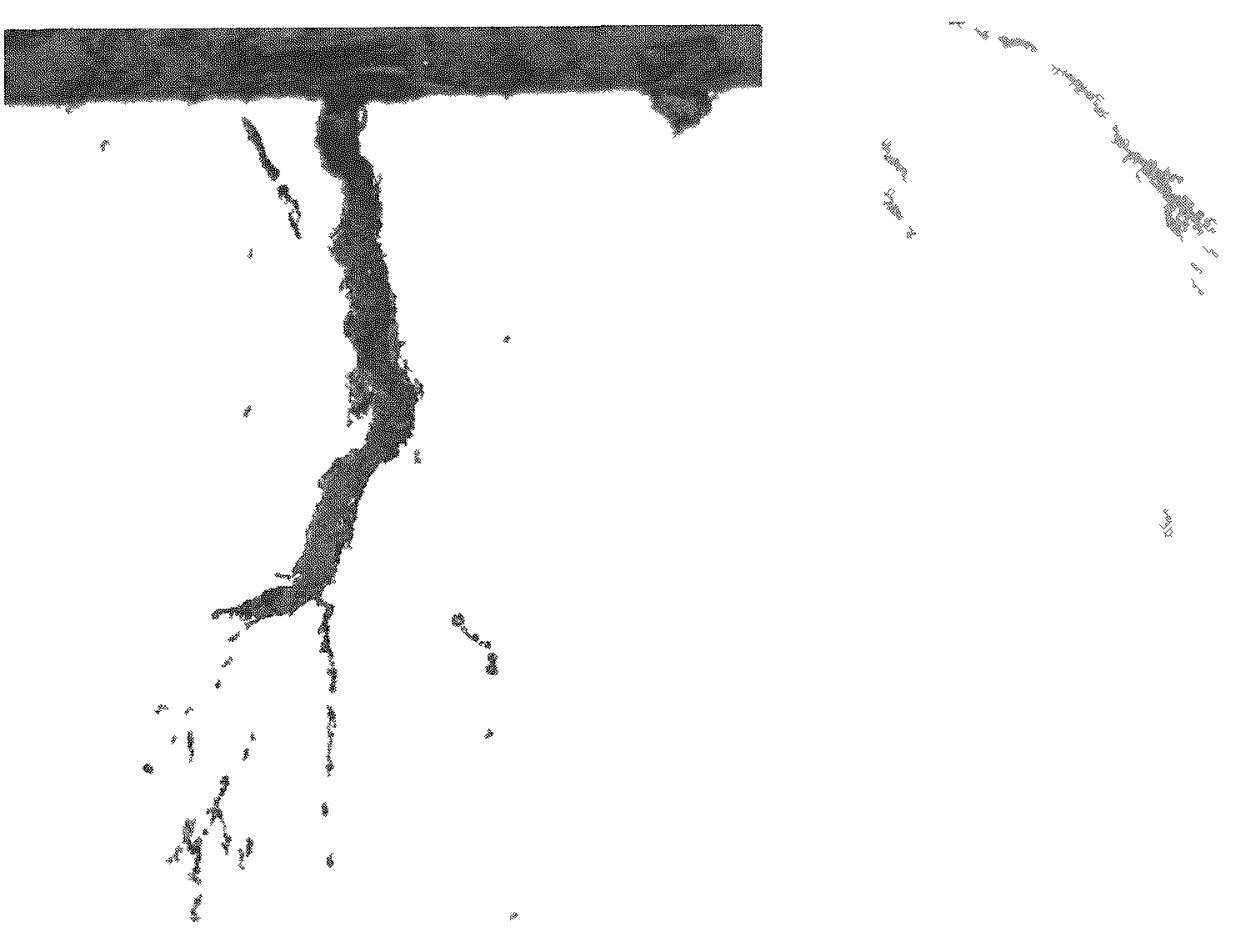

FIGURE 19. PHOTOMICROGRAPHS OF CROSS SECTIONS OF CRACKS IN TUBE STUBS 10 AND 18 AT THE JUNCTURE WITH THE DRAIN -SIDE SURFACE OF THE INNER TUBE SHEET AT THE INLET END Diagonal sections are illustrated here. 

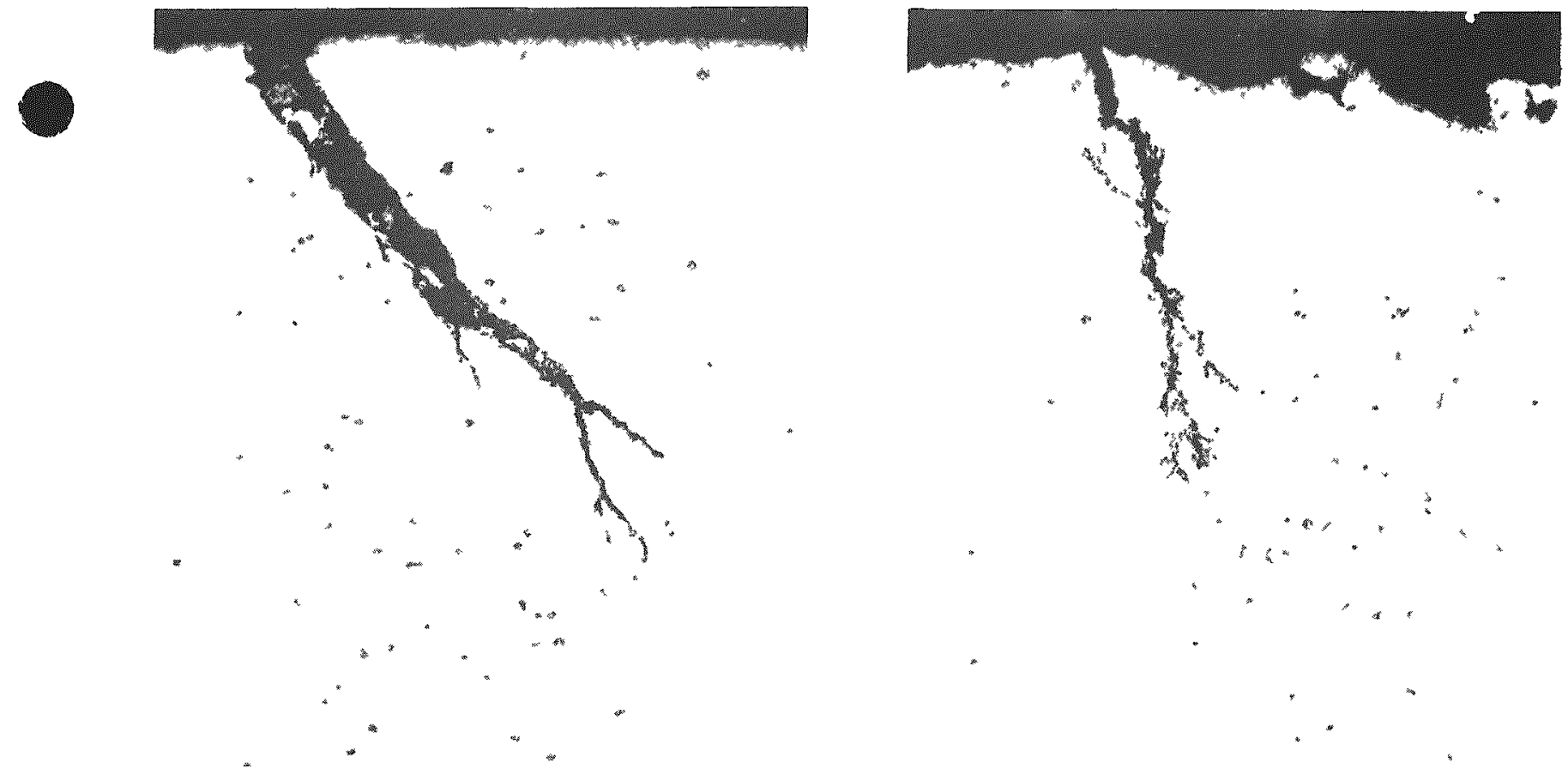

$100 \mathrm{X}$

C829

$100 \mathrm{X}$

C831
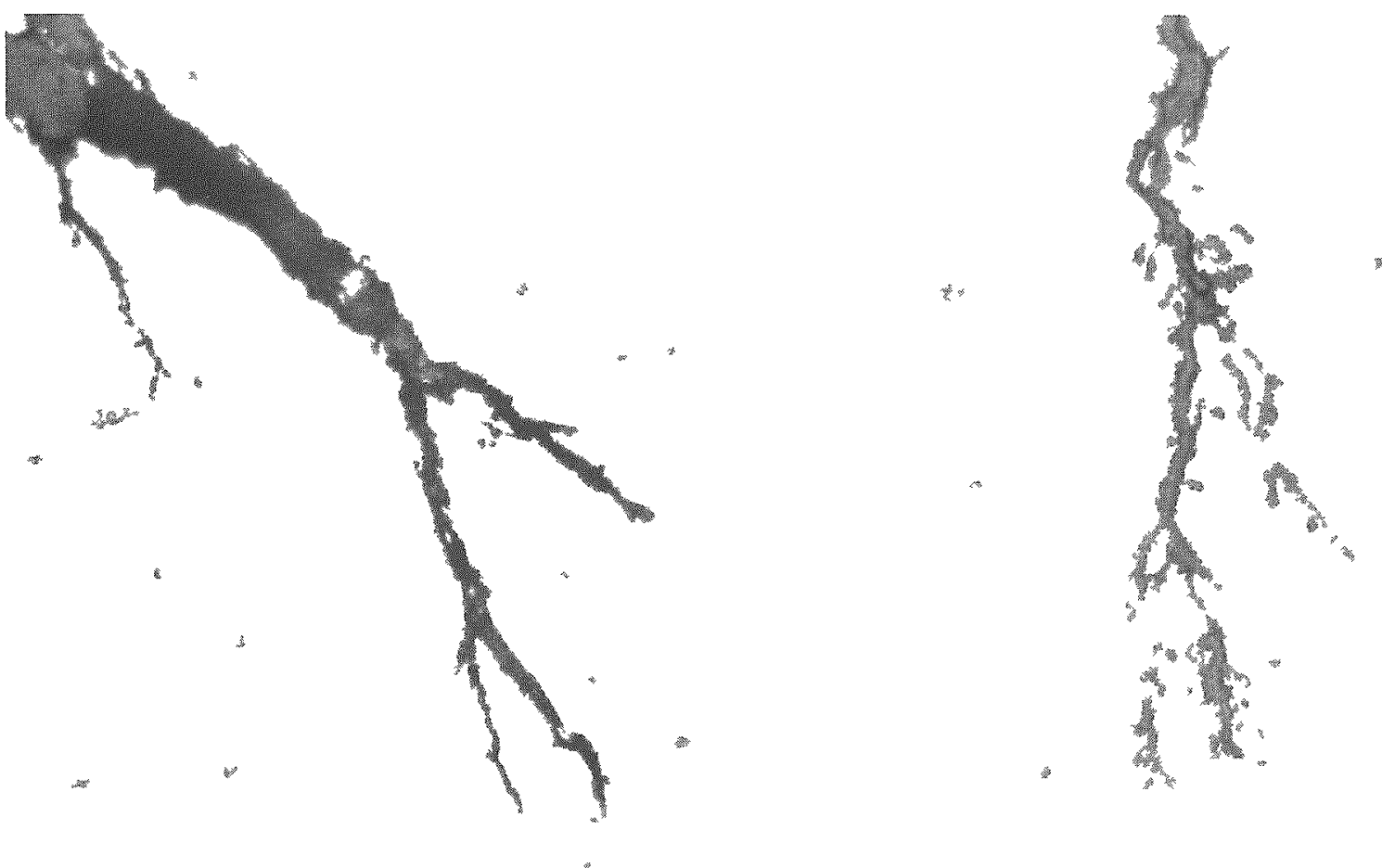

$250 \mathrm{X}$

T ube Stub 22

C830

$250 x$

Tube Stub 30

C832

FIGURE 20. PHOIOMICROGRAPHS OF CROSS SECTIONS OF TUBE STUBS 22 AND 30 AT THE JUNCTURE WITH THE DRAIN-SIDE SURFACE OF THE INNER TUBE SHEET AT THE INLET END

Duagonal secuons are shown. 


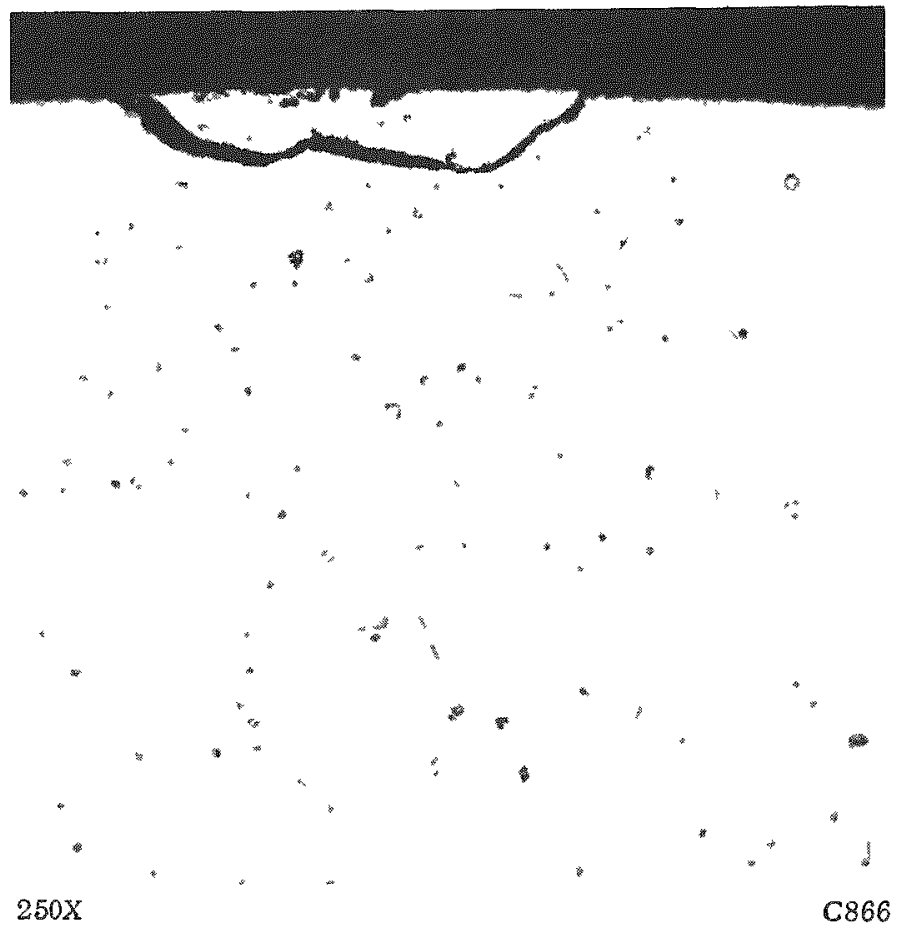

FIGURE 21. PHOTOMICROGRAPH OF CROSS SECTIONS OF COLD SHUT IN TUBE STUB 22 FROM THE OUTER TUBE SHEET AT THE INLET END

A transverse section is shown.

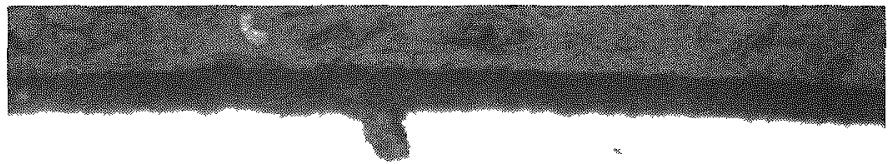

FIGURE 22. PHOTOMICROGRAPH OF CROSS SECTION THROUGH A SURFACE DEFECT ON TUBE STUB 14 FROM THE INNER TUBE SHEET AT THE OUTLET END 

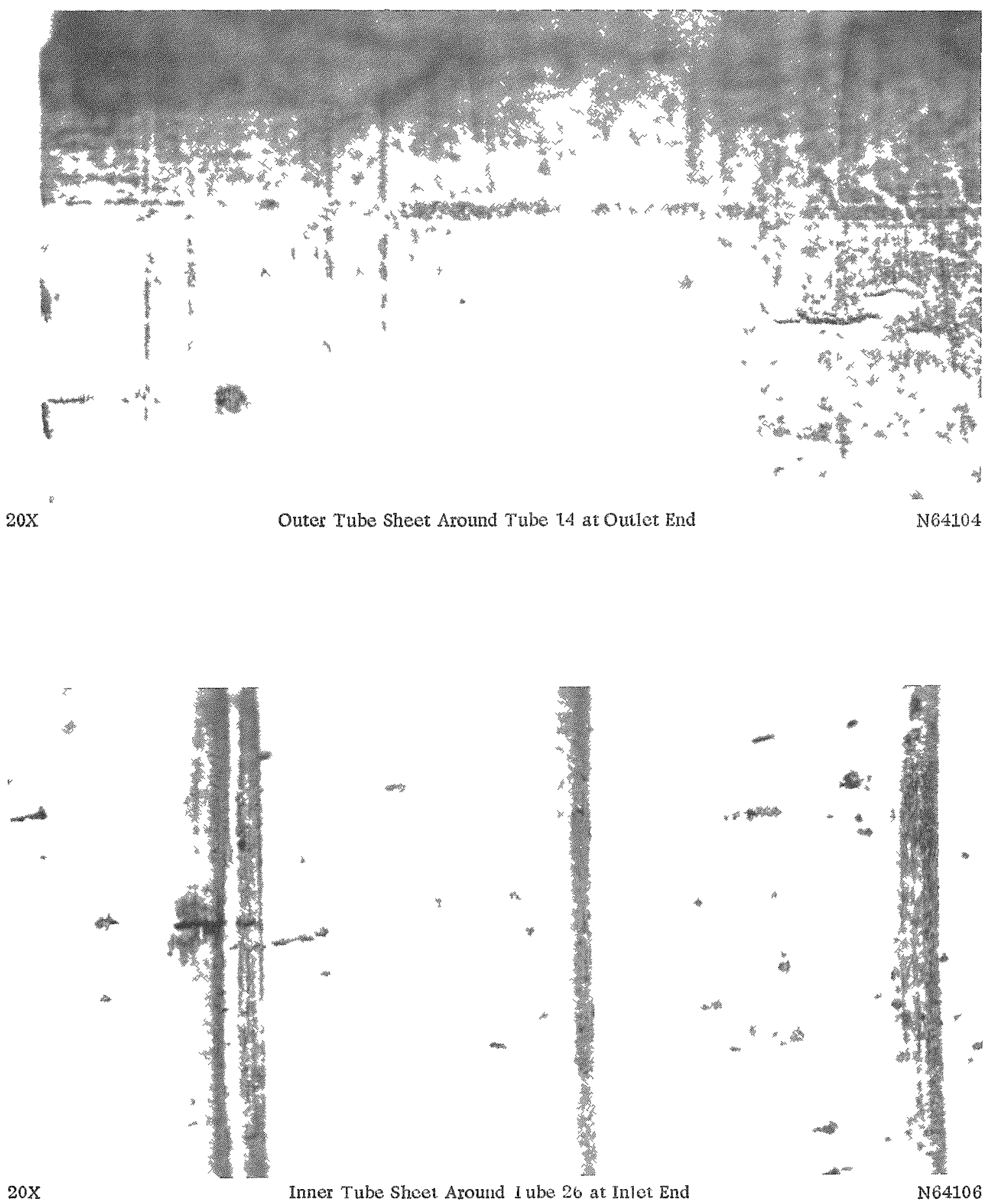

FIGURE 23. SURFACE APPLARANCE OI CRACK INDICATIONS IN TUBE-SHEET SLGMENTS

Tubing expansion grooves are visible around Tube 26. Nore wie cracks or tears in sheet around [ube 14 and the smeared metal at the crack indications in region around Tube 26. 

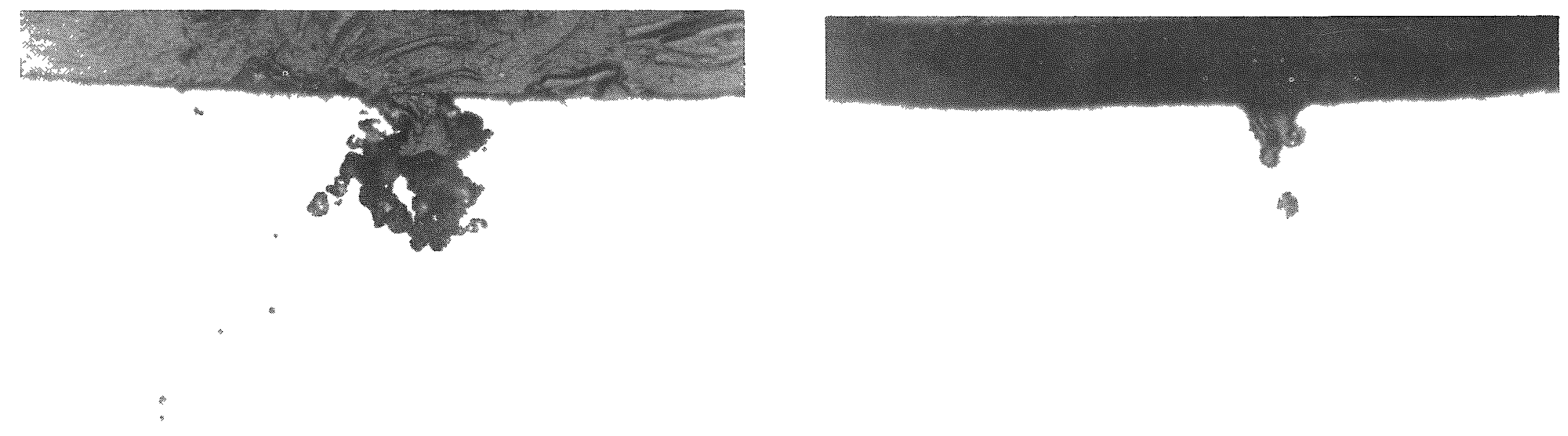

$250 \mathrm{X}$

Outer Tube Sheet Around Tube 14

C834

$250 \mathrm{X}$
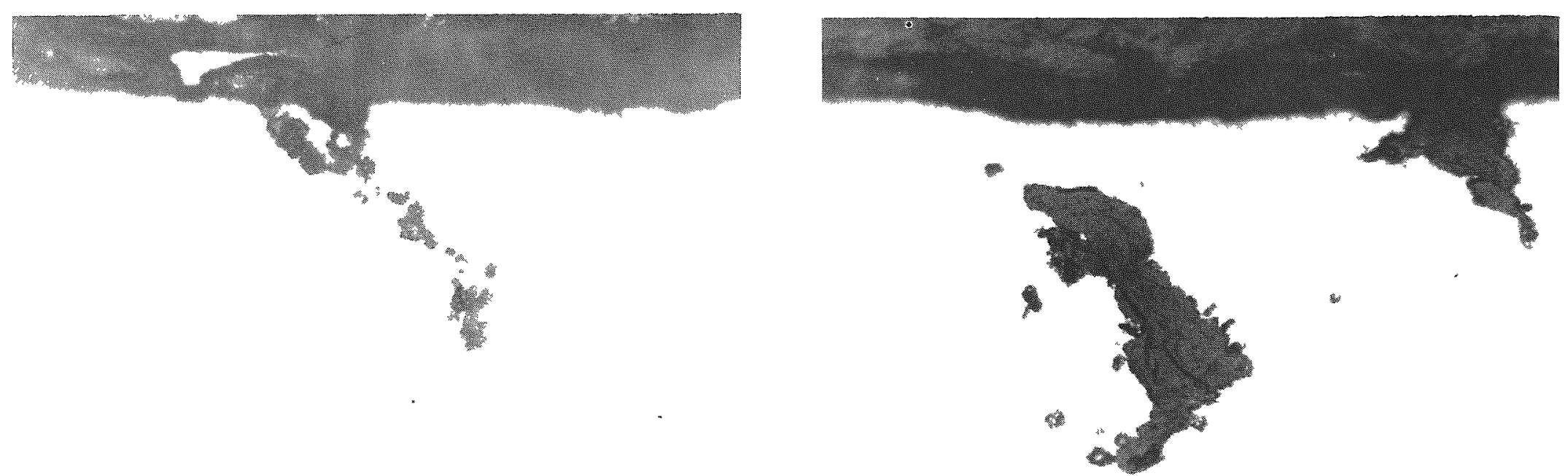

$250 X$

Outer Tube Sheet Around Tube 18

C835

$250 \mathrm{X}$

Inner Tube Sheet Around Tube 26

C839

FIGURE 24. PHOTOMICROGRAPHS OF CROSS SECTIONS THROUGH SURFACE DEFECTS IN TUBE-SHEET SEGMENTS FROM THE INLET END OF THE NONREGENERATIVE HEAT EXCHANGER

Note roughened appearance in sheet segments around Tube 14, laps or seams around Tubes 18 and 26, and large inclusion around Tube 26. Transverse sections are illustrated here. 


\section{-}

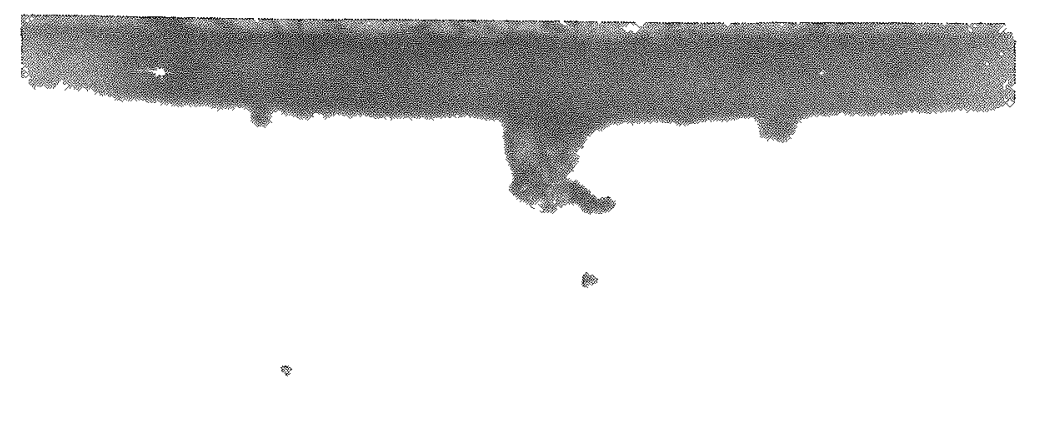

凃迹

$250 \mathrm{X}$
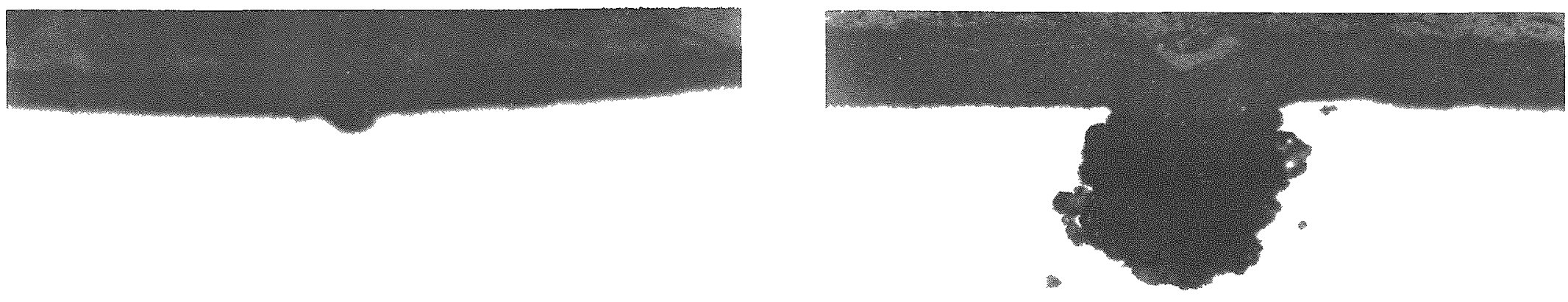

FIGURE 25. PHOTOMICROGRAPHS OF CROSS SECTIONS THROUGH SURFACE DEFECTS IN TUBE-SHEET SEGMENTS FROM THE OUTLET END OF THE NONREGENERATIVE HEAT EXCHANGER

Note large defects in segments around Tubes 22 and 30 from inner tube sheet. Transverse sectuons are shown. 
Tube Sheets Surrounding Tube Stubs

The results of the examinations of the tube sheets surrounding the seven tubes are summarized in Table 5. Indications of cracks or tears were found in three of the tube sheets before macroetching and in all four after macroetching. Examples of the surface appearance of the se indications are shown in Figure 23.

Metallographic examination of the suspected areas revealed evidence of stresscorrosion cracking in only one tube-sheet hole of the 28 examined. Cross sections through the other suspected areas revealed surface defects with both rounded and ir regular sidewalls and bottoms. Photomicrographs of typical areas are shown in Figures 24 and 25. Corrosion product was found in some of the surface defects. However, it appeared that the defects were not a result of corrosion, but that corrosion occurred when or after the defect was formed. For example, air entrapped in voids during melting might oxidize the walls of the void during forging and the voids might not seal. Another possibility might be corrosion in a mechanically produced defect within the tube sheet from entrapped electrolyte and the depletion of oxygen within the crevice.

The cracking which was observed in the one tube-sheet hole occurred just at the surface on the tube-sheet drain side around Tube 30 in the inner tube sheet at the inlet end where seepage and red rust were observed. The crack was branching and transgranular and had a maximum depth of $10 \mathrm{mils}$. A photomicrograph of the cross section of this crack is shown in Figure 26.

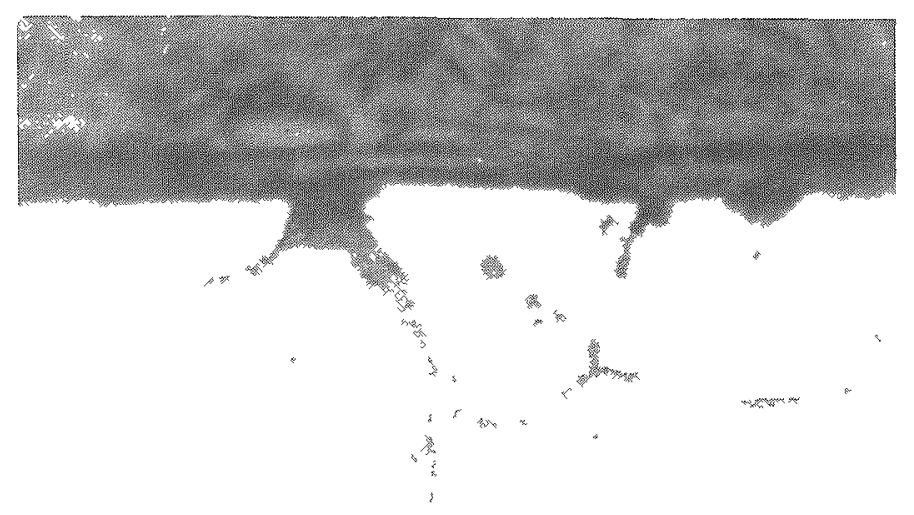

FIGURE 26. PHOTOMICROGRAPH OF CROSS SECTION OF CRACK IN THE INNER TUBE SHEET SURROUNDING TUBE 30 AT THE INLET END

Note the transgranular, branching nature of the crack. A transverse section is shown. 
TABLE 5. RESULTS OF EXAMINATIONS OF TUBE-SHEET SEGMENTS FROM THE NONREGENERATIVE HEAT EXCHANGER

\begin{tabular}{|c|c|c|c|}
\hline \multirow[b]{2}{*}{ Hole } & \multicolumn{2}{|c|}{ Location of Possible Cracks(a) } & \multirow[b]{2}{*}{ Results of Metallographic Examination } \\
\hline & Before Descaling & After Descaling & \\
\hline \multicolumn{4}{|c|}{ Outer Tube Sheet at Inlet End } \\
\hline 6 & None & $1 / 16$ to $1 / 4$ at $3: 00,7: 00(b)$ & Transverse section; no cracks; rounded groove, maximum depth: 2 mils \\
\hline 10 & None & $1 / 4$ at $3: 00,7: 00^{(b)}$ & Transverse section; no cracks or pits \\
\hline 14 & 0 to $1 / 8$ a: $6: 00$ & 0 to $1 / 8$ at $6: 00$ & $\begin{array}{l}\text { Transverse section; no cracks; roughened groove, maximum depth: } \\
4 \text { mils }\end{array}$ \\
\hline 18 & None & $1 / 16$ to $1 / 4$ at $6: 00,8: 00,9: 00(b)$ & Transverse section; no cracks; lap or seam, maximum depth; 6 mils \\
\hline 22 & None & 0 to $1 / 4$ at $1: 00,9: 00(b)$ & $\begin{array}{l}\text { Transverse section; no cracks; roughened groove, maximum depth: } \\
2 \text { mils }\end{array}$ \\
\hline 26 & None & $3 / 8$ at $5: 00(b)$ & Transverse section; no cracks; small groove, maximum depth: $0.5 \mathrm{mil}$ \\
\hline 30 & None & $1 / 32$ at $12: 30$ & Transverse section; no cracks; small groove, maximum depth: 0.5 mil \\
\hline \multicolumn{4}{|c|}{ Inner Tube Sheet at Inlet End } \\
\hline 6 & None & $1 / 4$ to $1 / 2$ at $2: 00,6: 00,9: 00(b)$ & Transverse section; no cracks; groove, maximum depth: 1.5 mils \\
\hline 10 & None & None (b) & Not examined \\
\hline 14 & None & None (b) & Not examined \\
\hline 18 & None & $1 / 2$ at $8.00(b)$ & Transverse section; no cracks; small groove, maximum depth: $0.25 \mathrm{mil}$ \\
\hline 22 & None & $1 / 16$ to $1 / 2$ as $9: 00$ to $1: 00(b)$ & Transverse section; no cracks; groove, maximum depth: 2 mils \\
\hline 26 & None & $1 / 4$ to $1 / 2$ atc $5: 00,12: 00^{b}$ b) & Transverse section; no cracks; lap or seam, maximum depth: 5 mils \\
\hline 30 & None & 0 to $1 / 2$ at $5: 00,9: 00,11: 00^{(b)}$ & Transverse section; branching crack, maximum depth: 10 mils \\
\hline \multicolumn{4}{|c|}{ Inner Tube Sheet at Outlet End } \\
\hline 6 & None & Nond (b) & Nor examined \\
\hline 10 & None & $1 / 4$ to $1 / 2 a t: 00(b)$ & Transverse section; no cracks; groove, maximum depth: 2.5 mils \\
\hline 14 & None & None $(b)$ & Not examined \\
\hline 18 & None & $1 / 2$ at $9: 00(b)$ & Transverse section; no cracks, pits, or grooves \\
\hline 22 & $1 / 4$ as $7: 00,8: 00$ & $1 / 4$ at $7: 00,8: 00$ & Transverse section; no cracks, large seam, maximum depth: 5 mils \\
\hline 26 & None & $1 / 8$ to $1 / 2$ at $3: 00,7: 00^{(b)}$ & Transverse section; no cracks, pits, or grooves \\
\hline 30 & None & $1 / 2$ at $1: 00^{(b)}$ & Transverse section; no cracks; large groove, maximum depth: 5 mils \\
\hline
\end{tabular}


TABIE 5. (Contuned)

\begin{tabular}{|c|c|c|c|}
\hline \multirow[b]{2}{*}{ Hole } & \multicolumn{2}{|c|}{ Location of Possible Crachs (a) } & \multirow[b]{2}{*}{ Results or Metallographic Exanination } \\
\hline & Before Jyescaling & Afer Descalug & \\
\hline \multicolumn{4}{|c|}{ Onter Tube Sheet at Outlet End } \\
\hline$\because$ & None & None $(b)$ & Not examined \\
\hline $1 \%$ & $1 / 1 \mathrm{k}, \mathrm{at} 10000$ & $110 \% 1 / 4$ ar $4: 00,1.2000$ & Longitudinal section; no cracks; groove, maximum depth: ${ }_{-0}^{3} 5 \mathrm{~m}$ mis \\
\hline 4 & None & None (b) & Not examined \\
\hline 18 & sone & None (b) & Transverse section; no indications \\
\hline $\operatorname{sog}_{0}$ & None & None (b) & Transverse section; no indications \\
\hline 20 & Sone & None (b) & Not examined \\
\hline $3 n$ & $1 / 4103 / x$ at $4: 04$ & 0 to 3/8 at $2: 00,1: 00,7: 00,16: 00$ & Transverse section; no cracks; small groove, maximum depth: I mil \\
\hline
\end{tabular}

(a) All craet indications were longitudinal on walls of tube-sheet holes. Fraction is distance from secondary face of tube sheet in inches. Clock designation indicates position on circumference of tubing hole as vewed from the inlet end lookng toward the outlet end.

(b) Macroetchod in addition to chemical descaling. 
Flat Surfaces of Tube Sheets

In addition to the tube-sheet holes, the flat surfaces of the tube sheet surrounding the seven tubes (normal to the tubing) also were examined. A portion of the secondary side (or side nearest the secondary water) of the tube sheet surrounding two holes from each tube sheet was mounted for metallographic examination. The plane of examination was normal to the direction of the tubing and was just below the secondary surface of the tube sheet. The following areas were examined in this fashion:

Inlet end

Outer tube sheet surrounding Tubes 10 and 26

Inner tube sheet surrounding Tubes 6 and 18

Outlet end

Outer tube sheet surrounding Tubes 18 and 30

Inner tube sheet surrounding Tubes 18 and 22.

No cracks were found on the secondary surface of any of the tube sheets.

Cracks were detected, however, on the flat surfaces of the drain side of the inner tube sheet at the inlet end. The cracks were detected in preparing the tube-sheet specimen surrounding Tube 30 (see Figure 26) for metallographic examination. A montage of the cracks detected is shown in Figure 27. The branching crack presented in Figure 26 is shown near the bottom xight. The appearance of the other cracks suggested that they were being viewed from the surface rather than in cross section. Accordingly, the specimen was broken from the mount and was rotated 90 deg to view the cracks in cross section (viewing plane was parallel to the tubing direction). Branching transgranular cracks with a maximum depth of 12 mils were detected. A photomicrograph of the deepest of the cracks is shown in Figure 28.

The drain-side surfaces of the remaining tube-sheet specimens also were examined visually at 20 diameters of magnification. Surface cracks were found on two additional specimens: around Tube 30 in the outer tube sheet at the inlet end and around Tube 6 in the inner tube sheet at the inlet end. The surface appearance of these cracks is shown in Figure 29. Photomicrographs of cross sections through the cracks are presented in Figure 30. The cracks were branching and transgranular with a maximum depth of 12 mils around Tube 6 and 4 mils around Tube 30.

The cracking of the inner tube sheet at the inlet end was probably associated with the observed seepage and solids concentration (chlorides) around the tube. The cracking around Tube 30 on the outer tube sheet at the inlet end may have resulted from water in the drain area being splashed onto the surface and chlorides being concentrated when this water evaporated. Rust stains on the outer tube sheet indicated that some water had been in the drain area. The source of this water was presumed to be from the seepage of secondary water past the expanded tubes.

\section{Baffle Plates}

Three baffle plates were selected for examination, one from each end and one from the middle (Plates 1, 24, and 48). The baffle plates were covered with the tan 


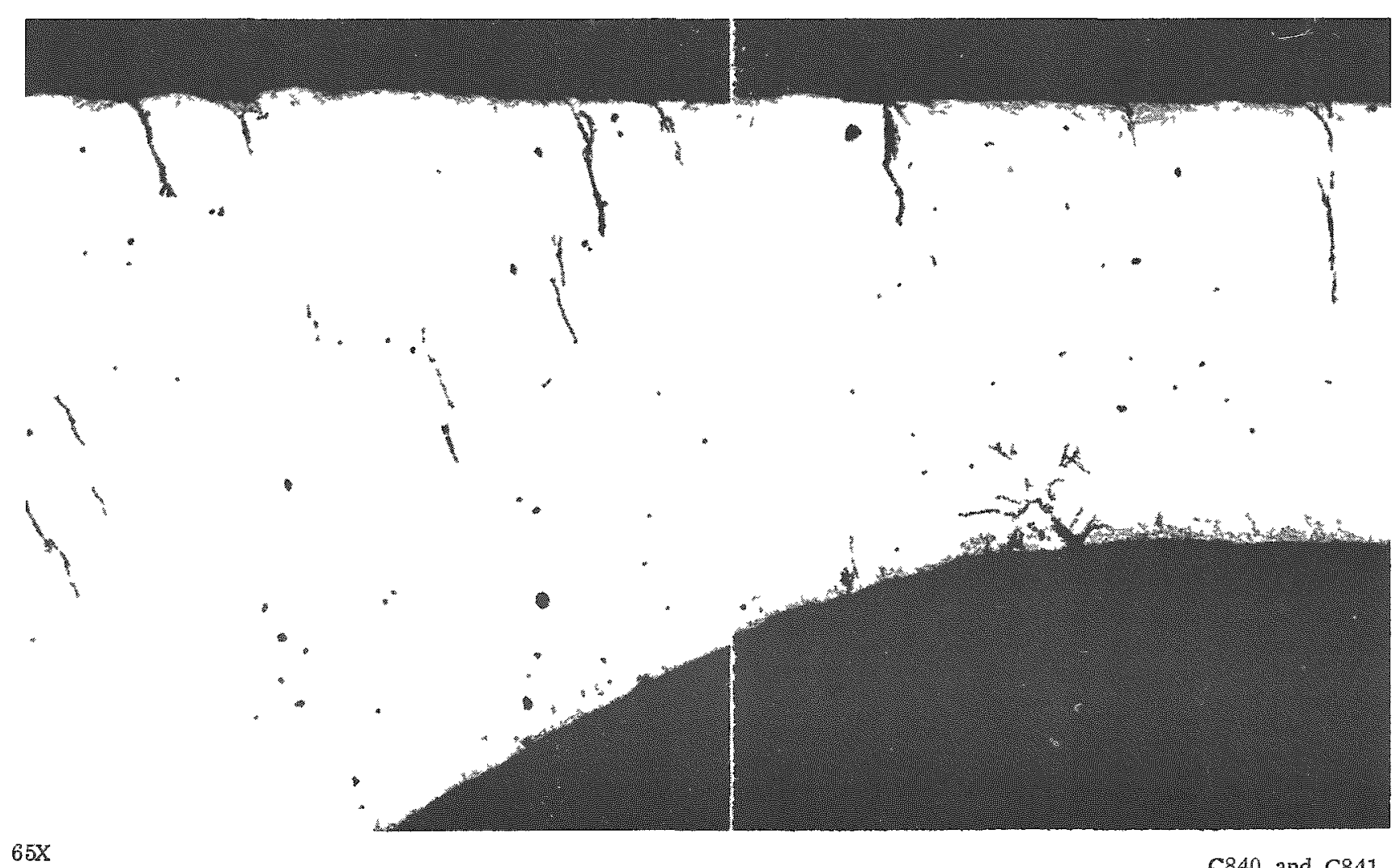
FIGURE 27. MONTAGE OF PHOTOMICROGRAPHS REVEAIING APPEARANCE OF CRACKS ON THE DRAIN-SIDE SURFACE OF THE INNER TUBE SHEET
SURROUNDING TUBE 30 AT THE INLET END

The branching crack at the lower right is a cross section of the crack shown in Figure 26. A transverse section is shown here. 


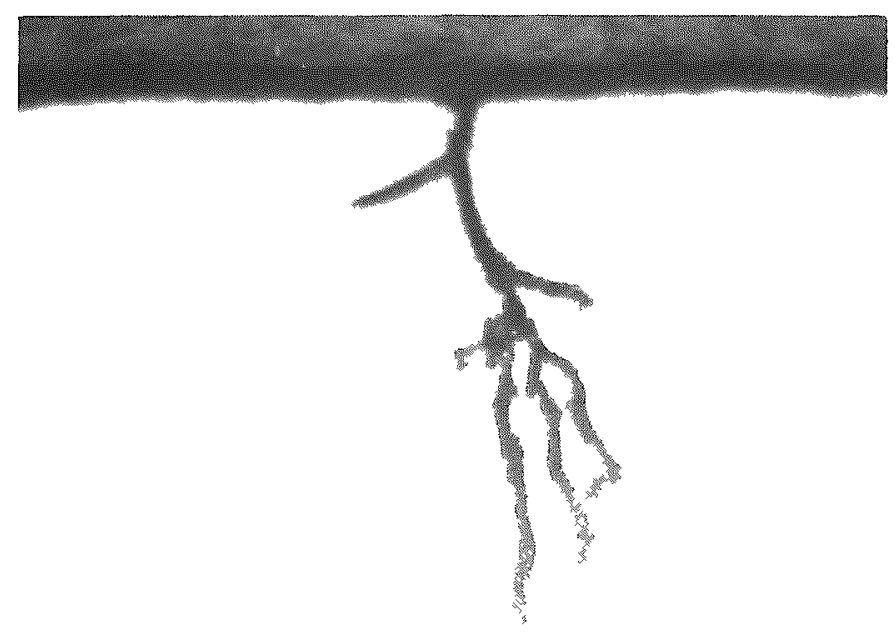

$250 \mathrm{X}$

C869

FIGURE 28. PHOTOMICROGRAPH OF A GROSS SECTION THROUGH A CRACK ON THE DRAIN SURFACE OF TIE INNER TUBE SHEET SURROUNDING TUBE 30 AT THE INLET END

See Figure 27 for the surface appearance of these cracks. A longitudinal section is illustrated here. 

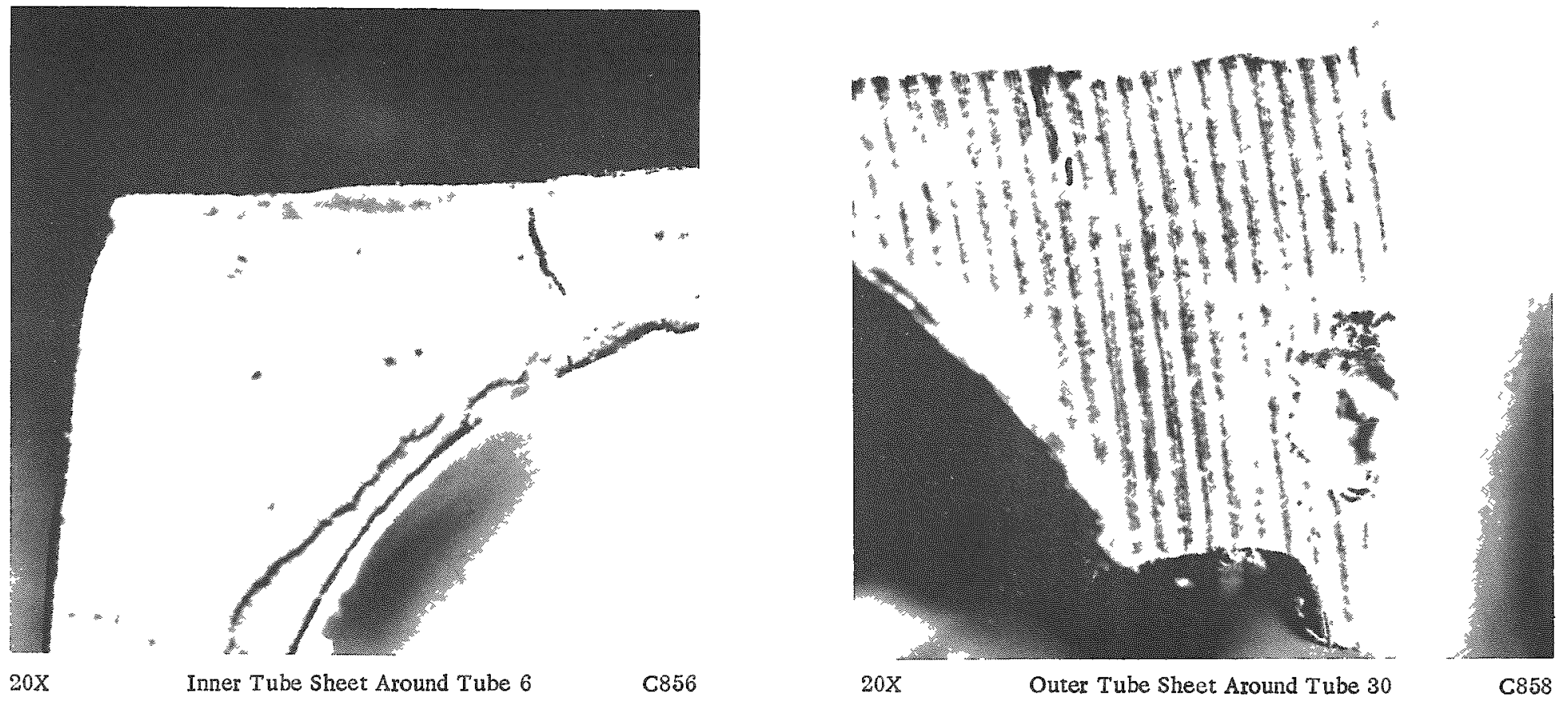

FIGURE 29. SURFACE APPEARANCE OF CRACKS ON THE DRAIN-SIDE SURFACE OF TUBE SHEETS AT THE INLET END The cracks in the photomicrograph of Tube 30 have been traced in ink for ease of detection. 

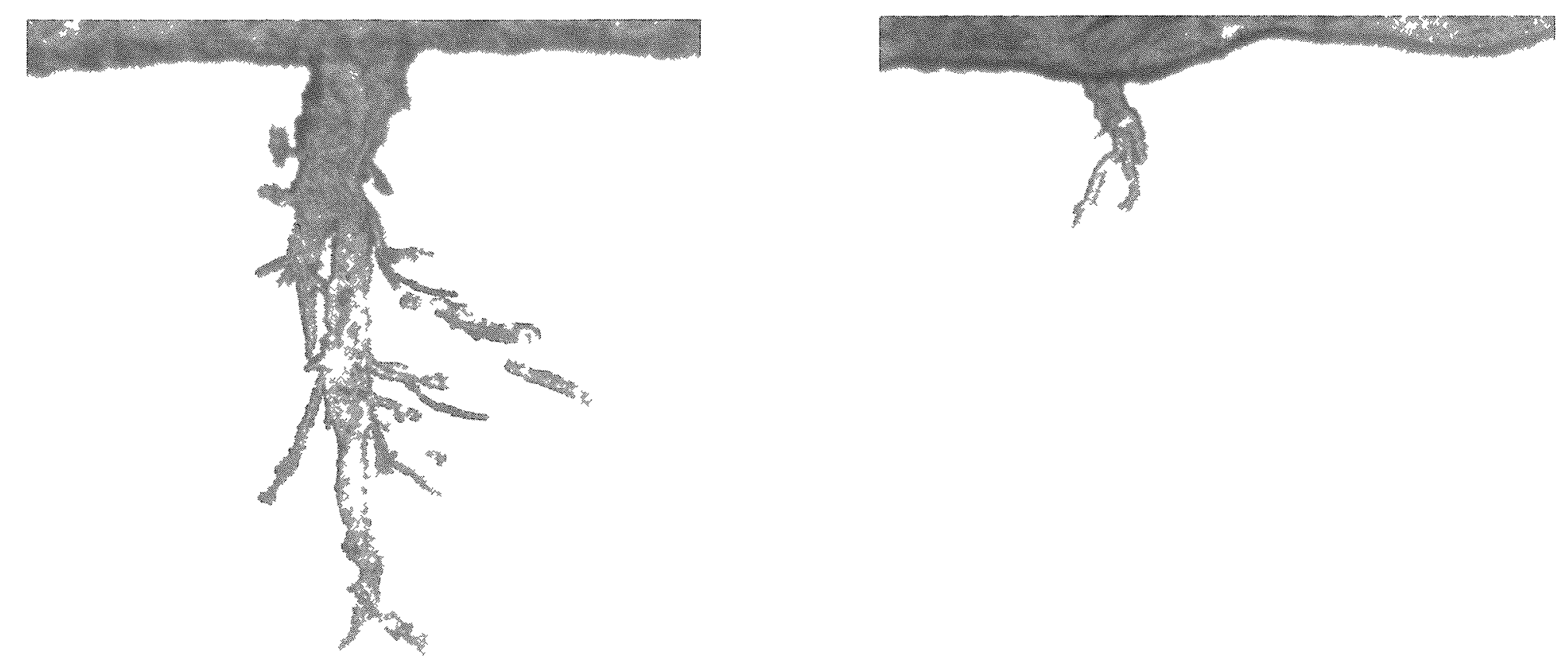

$250 \mathrm{X}$

Inner Tube Sheet Around Tube 6

C862

$250 \mathrm{X}$

Outer Tube Sheet Around Tube 30

C861

FIGURE 30. PHOTOMICROGRAPHS OF CROSS SECTION OF CRACKS IN THE DRAIN-SIDE SURFACES OF THE TUBE SHEETS AT THE INLET END OF THE NONREGENERATTVE HEAT EXCHANGER

See Figure 29 for the surface appearance of these cracks. Longitudinal sections are shown. 
deposit, but possessed a metallic luster beneath the deposit. No cracks or pits were observed on the baffle plates prior to macroetching. However, after macroetching, severe pitting was noted on the walls of the holes in the baffle plates. Metallographic sections through these pits revealed that they were associated with laminar zones in the microstructure of the stainless steel. These zones were presumed to be impurities (probably carbides) and were oriented in the rolling direction. A photomicrograph of a cross section of a pitted area is shown in Figure 31.

\section{Seal Welds}

The seal welds on the primary faces of the inlet and outlet outer tube sheets exhibited a dull metallic luster and were not descaled. They were examined visually at 20 diameters of magnification and by dye-penetrant check. There was rather good correlation between the two methods. The dye-penetrant check revealed cracks on all but two of the tubes which the visual examination indicated were cracked. The results of the examinations are summarized in Table 6. Cracks were detected in 5 of the 35 seal welds at the inlet end and in 11 of the 35 seal welds at the outlet end. The surface appearance of one of the more obvious cracks is shown in Figure 32.

Cross sections through selected cracks indicated that they did not penetrate to the annulus between the tube and tube sheet (this would have resulted in a leak into the tubesheet drain area). Photomicrographs of these sections are presented in Figures 33 and 34. The maximum depth of cracking in the sectioned specimens was 64 mils. This was within 12 mils of the tube-to-tube sheet annulus. The cracks did not have the appearance of stress cracks. They probably developed during welding as a result of a hot-short condition (due to lack of ferrite).

\section{DISCUSSION}

It is interesting to note that only one possible stress-corrosion crack was found in all the components which were exposed directly to the secondary water. This crack was only 2.5 mils deep and was associated with an obvious defect in the exposed tubing. The crack was located approximately in the middle of the heat exchanger. At this location, the temperature of the primary and secondary waters would be well below the maximum of $260 \mathrm{~F}$ and $164 \mathrm{~F}$, respectively. The surface temperature of the tubing would undoubtedly be above that of the secondary water. Stress-corrosion cracking of austenitic stainless steel has been observed in waters of similar composition at temperatures as low as $165 \mathrm{~F}$. (3) Thus, the one crack which was found was not unexpected, especially since the chloride concentration was about $1000 \mathrm{ppm}$ in the deposits on the tube.

On the other hand, the low incidence of cracking in the secondary portion would be anticipated. Because of the low temperatures and the 75-psi pressure on the secondary side, there was little likelihood of localized boiling with the resultant concentration of chlorides in crevice areas involving heat-transfer surfaces.

Rather severe stress-corrosion cracking was found in the tubing at the juncture with the drain-side surface of the inner tube sheet at the inlet end. Rust around the tubing and on the tube-sheet surface indicated that secondary water had seeped past the 


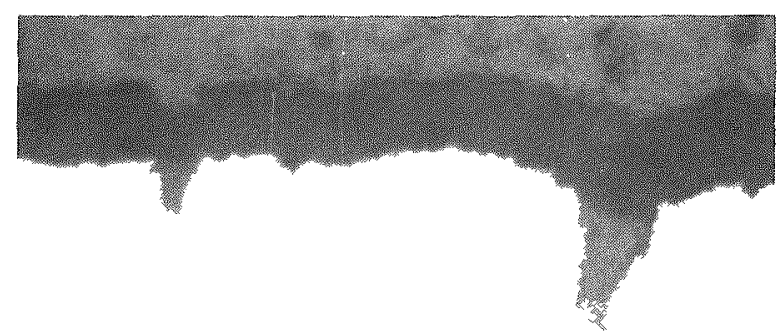

FIGURE 31. PHOTOMICROGRAPII OF A CROSS SECIION THROUGI PITS RESULTING FROM MACROLTCHING OF BAFFLE PLATES

Pits appear to be assoclated with Impunty stringers onented in the rolling durection. A longudunal section appears here.
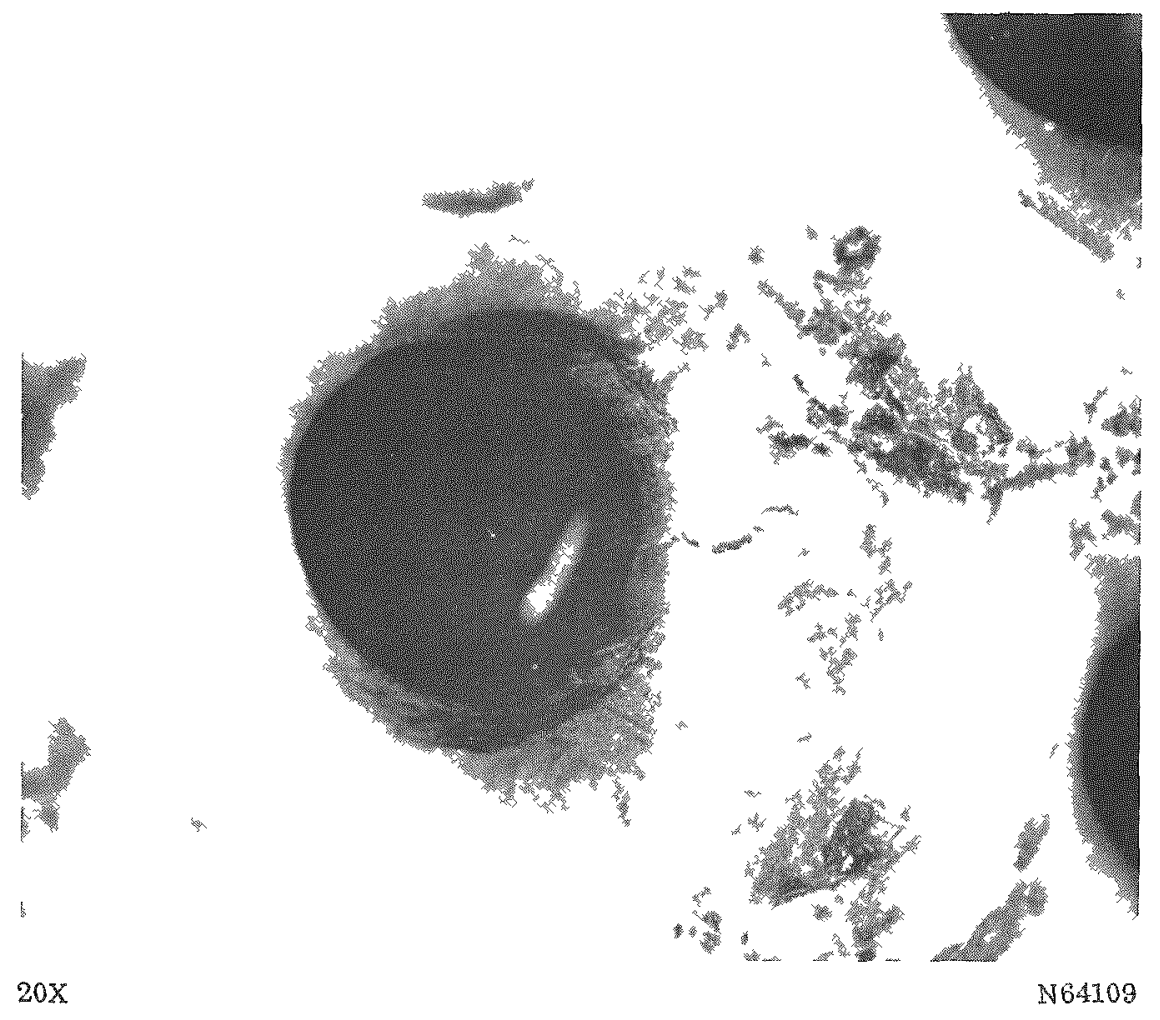

FIGURE 32. SURFACE APPEARANCE OF CRACK IN SEAL WELD ON TUBE 22 AT THE INLET PRIMARY FACE OF THE NONREGENERATIVE IEAT EXCHANGER

Note that crack estends into inside of surface of tubung. 
TABLE 6. RESULTS OF EXAMINATIONS OF SEAL WLLDS WHCH EXHUBTED CRACKING IN THE NONREGENERATIVE HEAT FXCHANGER

\begin{tabular}{lc}
\hline Indications of Possible Cracks(a) & Results of Motallographic Examination \\
Tube & at 30 Diameters of Magnification
\end{tabular}

\section{Inlet End}

Two radial cracks an $2: 00,3: 00(h)$
Not examined Not examined

'T'angential section at 45 deg: crack in weld, maximum deprha 17 miss

Tangenial section at 45 deg; crack in weld, maxinum depth: 36 unils

Not cxamined

\section{Onlel End}

Radial crack at 10:00

Radial crack ar $5: 30(\mathrm{~b})$

Two radial cracks at $4: 00,7: 00(\mathrm{~b})$

Radial crack at $5000(b)$

Radial crack and branching crack at 5:30(b)

Radial crack at $5.00(\mathrm{~h})$

Radial crack at $5: 00(b)$

Two radial cracks at $5: 00,6: 00$ (h)

Four small cracks ar 8.00 berween Tubes 30 and $33(\mathrm{~b})$

small crack ai $8: 00$ between Tubs $3 n$ and 34

small crack at 4:00 hetween Tubes 32 and $3.5(h)$
Not axamined

Not examined

Not examined

Nol examined

Nol uxamined

Jangential section at 45 deg; crack in weld, maximum depth: for mils

Tangential soction at 45 deg: crack in weld, maximun depth: $36 \mathrm{mils}$

Not examined

Not examined

Not examined

Not examined

(a) Clock designation indicates position on circumference of tubing as viewed from the inlct and looking toward the out let end.

(b) Cracking also detected hy dye -penerrant check. 

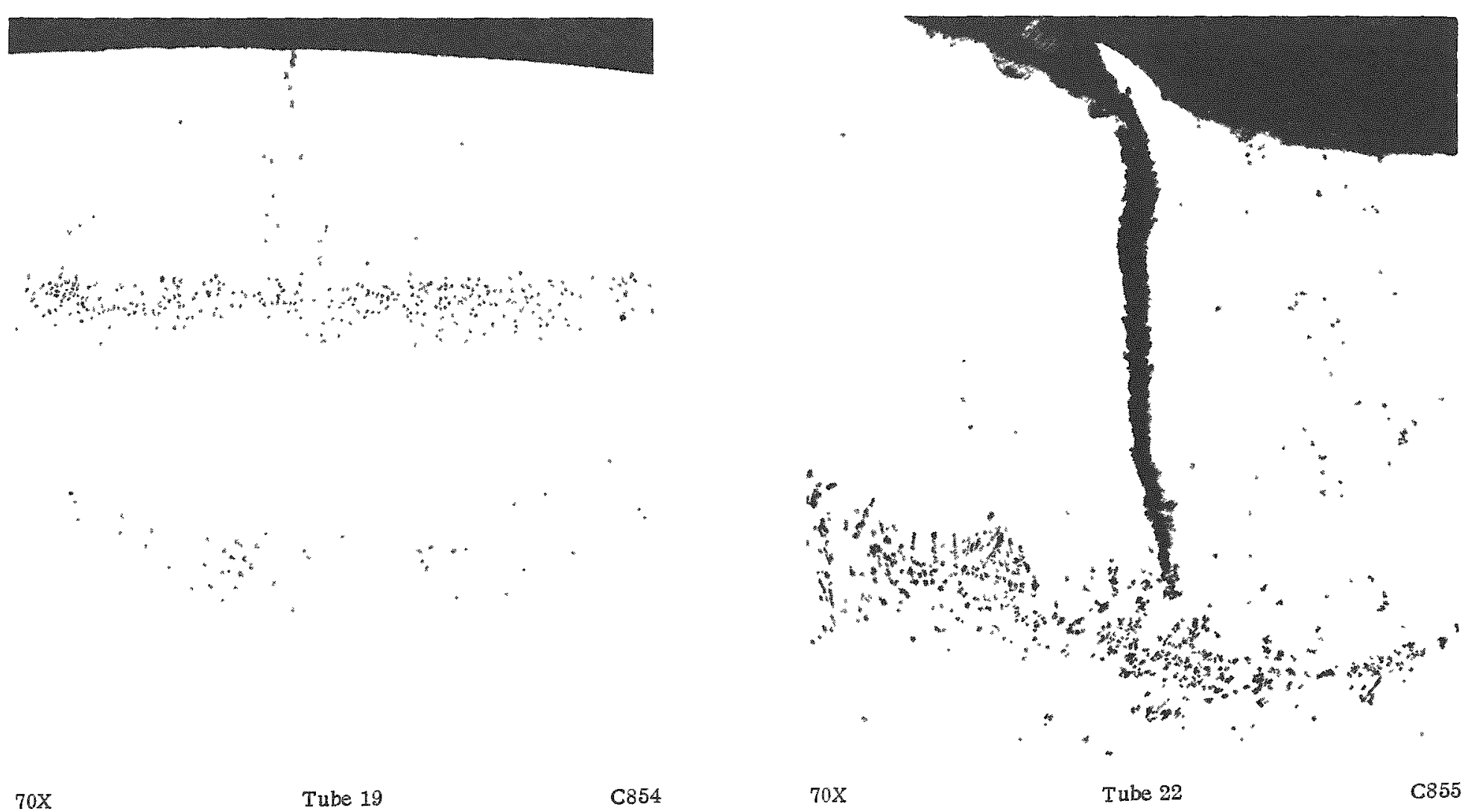

FIGURE 33. PHOTOMICROGRAPHS OF CROSS SECTIONS THROUGH WELD CRACKS IN SEAL WELDS AT THE INLET END OF THE NONREGENERATIVE HEAT EXCHANGER

See Figure 32 for the surface appearance of the crack in Tube 22. Diagonal sections (tangential) are shown here. 

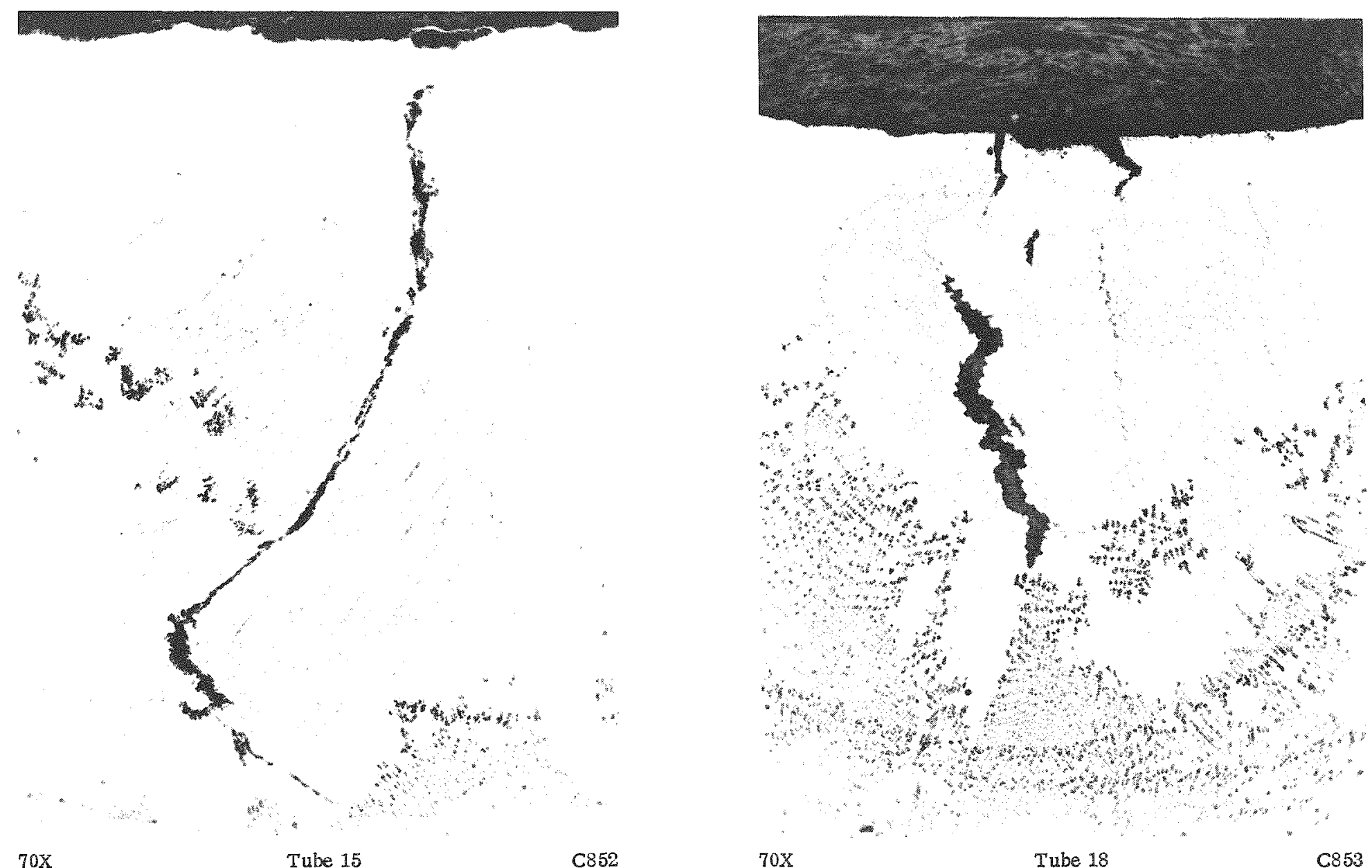

FIGURE 34. PHOTOMICROGRAPHS OF CROSS SECTIONS THROUGH WELD CRACKS IN THE SEAL WELDS AT THE OUTLET END OF THE NONREGENERATIVE HEAT EXCHANGER

The crack in Tube 15 was within 12 mils of the tube-to-tube sheet annulus. Diagonal sections (tangential) are shown. 
expanded tubes. It evaporated upon reaching the tube-shret drain area, resulting in increased chloride concentration. There was little or no cuoling in this area, and thus the temperature of the tubes would be near that of the inlet primaxy water $(260 \mathrm{~F})$. The expansion of the tubes had been carried just into the drain aree, which could account for the presence of tensile stresses in the tubing.

A somewhat similar explanation exists for the cracking on the drain-side surface of the inner tube sheet at the inlet end. The seeping water carried chlorides out onto the surface of the tube sheet where the water evaporated and the chlorides were concentrated. Residual stresses in the forging, plus surface stresses from machining, contributed to the cracking. The stress-corrosion cracking on the drain-side surface of the outer tube sheet of the inlet end probably was a result of the ship's motion, which caused periodic wetting of this area from water which stood in the bottom of the drain area. This water probably came from the seeping tubes and thus contained chlorides.

Leak tests conducted on the heat exchangex indicated that there were not leaks around the expanded tubes at room temperalure. It is possible that the corrosion product plugged the se leaks and acted as a seal against the leak-test pressure of 120 psia. It is also possible that differences in expansion because of temperature differences could have resulted in leaks at the operating temperature. In addition, the warped condition of the first $30 \mathrm{in.}$ of the tubing indicated that the normal $260 \mathrm{~F}$ primary-water inlet temperature may have been exceeded on one or more occasions. If such a condition were followed by a sudden influs of cooler primary water, the contraction of the tubing away from the hotter tube sheet could result in leakage. On the other hand, the warpage may have been the result of greater expansion of the tubing because of the temperature differential between the tubing and the shell which existed under normal operating conditions. Deformation of the tubing would be expected to take place at the inlet and where the tubing was hottest.

The results of the examination suggest that, in this paxticular application, stresscorrosion cracking of the stainless steel heat exchangex could be minimized by employing single-rather than double-tube-sheet construction.

The incidence and severity of cracking in the fully exposed tubes was low. Cracking was found in only one of the seven tubes examined. From a stalistical viewpoint, at the 95 per cent confidence level, this represonts a probability of finding cracking on fully exposed surfaces in 0 to 60 per cent(1) of the rest of the tubes in the heat exchangex. However, there was only one crack detected in the entire group of seven tubes. The depth of the crack was 2.5 mils or only about 7 per cent through the 35 -mil-thick tubing wall. All other indications on the exposed tubes were Cound to be longitudinal surface defects such as scratches, gouges, and cold shuts.

The incidence of cracking on the tube stubs at the drain-side juncture of the inner tube sheet at the inlet end was not only high, but the cracks were rulatively deep. Cracking in five of the seven tubes represents a cracking probability of 25 to 90 per cent at a 95 per cent confidence level. (4) The maximum depth of cracking was found to be 28 mils or 80 per cent penetration through the 35 -mil-thick tubing. Indications of cracks found within the tube sheet were not contirmed as cracks, and were believed to be similar to those found on the fully exposed tubes. 
Stress-corrosion cracks were found on the drain-side surfaces of the tube sheets at the inlet end. The incidence of cracking around the tubes was fairly low, being two in seven for the innex tube sheet and one in seven for the outer one. Depth of cracks was moderate, with the maximum being 12 mils. Since the tube sheets were $9 / 16$ in. (562 mils) thick, failure from complete penetration does not yet appear to be a problem.

Cracks were detected in 5 of 35 seal welds at the inlet end and in 11 of 35 at the outlet end. Several of the cracks were fairly deep, with one crack penetrating 64 mils or to within 12 mils of the tube-to-tube sheet annulus. It is believed that none of the cracks penetrated to the annulus between the tube and tube sheet. Leak tests, prior to examination of the unit, failed to reveal leaks at the seal weld. In addition, there was no evidence that primary water had leaked into the tube-sheet drain area. The cracks are believed to be fissures which developed during welding as a result of a lack of ferrite in the weldments (hot-short condition). These fissures probably propagated during reactor operation.

\section{CONCLUSIONS}

The following conclusions can be drawn from the results of the examination of the Low-temperature nonregenerative heat exchanger from the U.S.S. Nautilus (SSN-571):

(1) There is no serious stress-corrosion problem in any component normally in contact with the secondary water. Only one small crack, 2.5 mils deep, was found on surfaces exposed to secondary water.

(2) Stress-corrosion cracking is a serious problem at the drainside juncture of tubes and the inner tube sheet at the inlet end. Probable incidence of cracking in tubing at this location is 25 to 96 per cent on the basis of a 95 per cent confidence level. Maximum depth of cracking was found to be 80 per cent penetration of 35 -mil-thick tubing walls.

(3) Stress-corrosion cracks in the tube sheets were less than $13 \mathrm{mils}$ deep and do not pose a serious threat to operation of the unit.

(4) Cracking of seal welds could result in eventual leakage. This conclusion is based on the depth of observed cracks and the assumption that cracking will continue to progress.

\section{ACKNOW LEDGMENTS}

This work was conducted under WAPD Reference No. 73-100-929) for the Bettis Atomic Power Laboxatory operated for the Atomic Energy Commission by the Westinghouse Electric Corporation. Liaison was maintained with Mr. Herbert J. Kaplan of that laboratory, whose assistance has been greatly appreciated. The authors also wish to 
express their appreciation to Mr. James H. Saling and others of the Battelle Hot-Cell Facility who assisted in cutting up the heat exchanger and to Mr. William N. Stiegelmeyer of the Battelle Corrosion Research Division who conducted the metallographic examinations.

\section{REFERENCES}

(1) Golik, M. A., "Report on the Investigation of a Sample Water Cooler Which Failed Onboard the U.S.S. Nautilus (SSN-571) on February 23, 1956", WAPD-CTA(MEE)220 (August 8, 1957).

(2) Kaplan, H. J., "Report on the Investigation of a Second Sample Water Cooler Which Failed Onboard the U.S.S. Nautilus (SSN-571) on May 24, 1957", WAPD-CTA(MEA)1607.

(3) Brindley, W. F., and Scharfstein, L. R., "Stress Corrosion Testing of Austenitic Stainless Steels in Simulated Fresh Water Coolant", WAPD-CTA(MEE)-337 (January 3, 1958).

(4) Snedecor, G. M., Statistical Methods, 4th Edition, Iowa State College Press (1946), $\mathrm{p} 4$.

WEB:OMS: FWF/mab 